\title{
Engineering a Transmembrane Nanopore Ion Channel from a Membrane Breaker Peptide
}

Muralikrishna Lella and Radhakrishnan Mahalakshmi*

Molecular Biophysics Laboratory, Department of Biological Sciences, Indian Institute of

Science Education and Research, Bhopal, India-462023

*Corresponding author: maha@iiserb.ac.in

\section{Supporting Information}


a) Materials 3

b) Peptide Synthesis, Purification and Mass Spectrometric Analysis 3

c) Peptide Folding and Circular Dichroism (CD) Experiments 3

d) Planar Lipid Bilayer Experiments 4-5

i) Holding Voltage Measurements

ii) Voltage Ramp Measurements

iii) Data Analysis

\section{Supporting Table}

Table S1 List of peptides

Table S2 Dwell time values of channel open state for all chimeric peptides

\section{Supporting Figures}

Figure S1 Mass spectrometric analysis of peptides

Figure S2 Representative CD wavelength scans of thermal melting and recovery

Figure S3 Reverse engineered peptides show an increase in helicity with increasing temperature and prolonged incubation

Figure S4 Far-UV CD spectropolarimetric analysis of all chimeric peptides

Figure S5 rTM1 peptide shows stable ion channel activity for hours

Figure S6 Insertion of peptide and preassembly of channel in the membrane

Figure S7 Representative graphs of holding voltage measurements

Figure S8 Representative graphs of channel conductance

Figure S9 Representative graphs of dwell time calculation

Figure S10 Representative graphs for holding voltage measurements and dwell time distribution

Figure S11 Open probability calculation of single channel recordings

Figure S12 Observation of rTM1 ion channel behavior by $\mathrm{KCl}$ gradient, $\mathrm{pH}$ gradient and voltage ramp measurements

Figure S13 Schematic representation of charge distribution across the chimeric peptides for an ideal helical structure 


\section{MATERIALS AND METHODS}

\section{a) Materials:}

Dimethylformamide (DMF), trifluroacetic acid (TFA), 1,2-ethanedithiol (EDT), thioanisole N,N-diisopropylethylamine (DIPEA), phenol and lauryldimethylamine oxide (LDAO) were procured from Sigma-Aldrich Co., LLC. Rink Amide AM resin (200-400 mesh, $0.63 \mathrm{mmol} / \mathrm{g}$ loading capacity) was purchased from Novabiochem (EMD Millipore Chemicals). Fmoc amino acids and HATU ((dimethylamino)-N,N-dimethyl (3H- [1,2,3] triazolo [4,5-b] pyridin-3-yloxy) methaniminium hexafluorophosphate) were purchased from GL Biochem Ltd., Shanghai, China, hydroxybenzotriazole (HOBt) was from Spectrochem Pvt. Ltd., Mumbai, India, n-dodecylphosphocholine (DPC) and 1,2-diphytanoyl 3-phosphocholine (DiPhPC) were obtained from Avanti Polar Lipids (Alabaster, AL). All other chemicals were purchased from Merck Specialties Pvt. Ltd.

\section{b) Peptide Synthesis, Purification and Mass Spectrometric Analysis:}

All the peptides were synthesized by conventional solid phase peptide synthesis using Fmoc chemistry, as reported earlier. ${ }^{1,2}$ Briefly, peptides were synthesized on Rink Amide AM resin, and all the amino acids were activated and coupled using HOBt/DIPEA/HATU reaction cocktail in dry DMF. Fmoc removal was achieved using 20-30\% piperidine and the reaction was monitored at $301 \mathrm{~nm}$. After successful peptide synthesis, peptide cleaved from the resin by TFA: $\mathrm{H}_{2} \mathrm{O}$ : TIPS: phenol: EDT with the ratio of 82.5: 5: 5: 5: $2.5(100 \mu \mathrm{l} / 100 \mathrm{mg})$. The cleavage cocktail was removed from the reaction mixture by filtration of resin, efficient rotary evaporation, and the residual cocktail was removed by cold diethyl ether wash. The peptide was obtained as a dried powder at the end of the processing. Peptide powder was resuspended in water and lyophilized 2-3 times to remove any residual cleavage cocktail components. The final sample was achieved as a white peptide powder. Esquire 3000 Plus ion trap spectrometer and MALDI-ToF mass spectrometry (Bruker Daltonik GmbH, Germany) was used to confirm successful synthesis of the desired sequences (Table S1, Figure S1).

\section{c) Peptide Folding and Circular Dichroism (CD) Experiments:}

All spectroscopic studies were carried out using two detergent micelles, namely LDAO (lauryldimethylamine oxide) and DPC (n-dodecyl phosphocholine). Further, we used different concentrations of the detergent (LDAO: $4 \mathrm{mM}-100 \mathrm{mM}$; DPC: $5 \mathrm{mM}-50 \mathrm{mM}$ ). These conditions allowed us to assess whether the micelle headgroup or the detergent-peptide ratio (DPR) influenced our results. All the peptides were refolded by dissolving the peptide powder in $100 \mathrm{mM}$ LDAO and $50 \mathrm{mM}$ DPC (through a continuous process of sonication, heating and vortexing, until the solution became clear, as reported earlier. ${ }^{1}$ Samples were then centrifuged at $18000 \times \mathrm{g}$ to remove any particulate material. These samples were then quantified by absorbance using the molar absorption coefficient of $8480 \mathrm{~m}^{2} \mathrm{~mol}^{-1}$, and the concentration was adjusted to 0.022-0.024 mM using LDAO or DPC solution. This served as the stock refolded peptide. CD experiments were carried out on a JASCO J-815 CD spectropolarimeter (JASCO Inc., Japan) using $0.1 \mathrm{~cm}$ path length cuvette with $100 \mathrm{~nm} / \mathrm{min}$ scan speed, $0.5 \mathrm{~nm}$ data pitch and $1 \mathrm{~s}$ data integration time, at $25{ }^{\circ} \mathrm{C}$. All the wavelength scans were averaged over three acquisitions, and subtracted with the respective blank spectrum. Time-dependent secondary structure recordings 
were followed using the settings as stated above. Variable temperature melting experiments were carried out at every $5{ }^{\circ} \mathrm{C}$ from $5{ }^{\circ} \mathrm{C} \rightarrow 95^{\circ} \mathrm{C} \rightarrow 5{ }^{\circ} \mathrm{C}$ at the rate of $1{ }^{\circ} \mathrm{C} / \mathrm{min}$ and other parameters were as stated above. Peptide sample concentrations were $\sim 0.022-0.024 \mathrm{mM}$. CD values were converted into molar ellipticity (ME, deg $\mathrm{cm}^{2} \mathrm{dmol}^{-1}$ ), by correcting for the peptide concentration. Buffer used for the all CD experiments was $50 \mathrm{mM}$ phosphate $\mathrm{pH}$ 7.2.

\section{d) Planar Lipid Bilayer Experiments:}

Planar lipid bilayer (PLB) experiments were performed on a benchtop work station from Warner Instruments (Harvard Apparatus, Holliston, MA), as reported earlier. ${ }^{2}$ In brief, DiPhPC was used to form a membrane, which was dissolved in n-hexadecane at a concentration of 25 $\mathrm{mg} / \mathrm{ml}$. DiPhPC bilayer was painted over a $150 \mu \mathrm{M}$ aperture Delrin cup of $1 \mathrm{ml}$ capacity. All the PLB experiments were performed in $25 \mathrm{mM}$ phosphate buffer $\mathrm{pH} 7.2$ with $0.5 \mathrm{M} \mathrm{KCl}$ filled in both cis and trans chambers. The data was recorded at $10 \mathrm{kHz}$ frequency with low pass Bessel filter ( 8 pole) and digitized at $0.1 \mathrm{~ms}$ per point through the interface of Digidata 1440A (Molecular Devices, Sunnyvale, CA) and Clampex 10.3 software. For all the experiments, peptide dissolved in $5 \mu \mathrm{l}$ of $100 \mathrm{mM}$ LDAO was added to cis chamber and the final concentration of peptide achieved in the cis chamber was approximately 0.011-0.012 mM.

(i) Holding Voltage measurements:

Peptide was added to the PLB maintained at an applied voltage of $+10 \mathrm{mV}$. Once peptide insertion into the membrane, the system was checked for stable pore or channel forming behavior at $+10 \mathrm{mV}$. Holding voltage experiments were carried out by maintaining the positive and negative voltages for a minimum of 1 min recording, as illustrated below. Data acquisition was continued from $10 \mathrm{mV}$ to $100 \mathrm{mV}$ (in both positive and negative voltages).

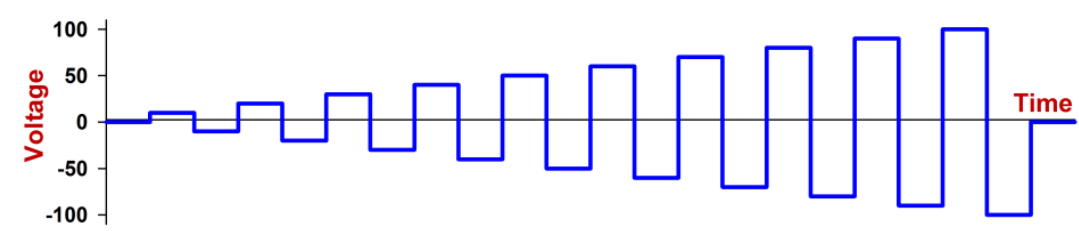

(ii) Voltage Ramp measurements:

After the formation of ion channel(s) at a holding voltage of $+10 \mathrm{mV}$ (as described in e(i), above), voltage ramp experiments were carried out at the rate of $5 \mathrm{mV} / \mathrm{s}$. In one acquisition, 4 complete recordings were obtained from $-100 \mathrm{mV}$ to $+100 \mathrm{mV}$. Three independent experiments were performed for reproducibility.

(iii) Data analysis:

To derive the open and low conductance states of the peptide pore (or) channel, conductance $(\mathrm{nS})$, dwell time calculations and open probability $\left(\mathrm{P}_{\mathrm{o}}\right)$ derivations were carried out using a 1-2 min data window from independent recordings. All analyses were carried out for the data acquired between $-100 \mathrm{mV}$ to $+100 \mathrm{mV}$, at steps of $10 \mathrm{mV}$. 
Holding voltage data was analyzed for the population of open and low conductance states at each applied voltage. For this, the selected data window was plotted as histograms of occurrences at each value of observed current, with bin width of 0.01 . The data was then converted to conductance $(\mathrm{G})$ with units of $\mathrm{nS}$, from the recorded current (in pA), using the formula $\mathrm{G}=$ [Current (in $\mathrm{pA}$ )] / [Applied voltage (in $\mathrm{mV}$ )]. These conductance histograms were fitted to a Gaussian distribution in peak function and the maximum observed state was derived. This data was then used to calculate the $G / G_{10}$ plots, where $G_{10}$ is the observed conductance at $+10 \mathrm{mV}$ (Figure S8). Gaussian fits were performed on OriginPro v9.0 and SigmaPlot v11.0.

For dwell time calculations, the current traces were first filtered using a low pass filter with a rate of $100 \mathrm{~Hz}$. The filtered current traces were aligned between zero and first order. Data shorter than $2 \mathrm{~ms}$ was omitted to reduce spurious noise detection from the observed current. The data were then processed using the default parameters available in the Clampfit v10.3 software. ${ }^{3}$ ${ }^{4}$ The obtained values were fitted to an exponential log probability function, with variable metric method. The histograms and dwell time values at each holding voltage mentioned above were plotted in logarithmic scale (Figure S9, Table S2). The complete analysis was carried out in Clampfit v10.3.

Open probability calculations were carried out for the observed single channels acquired at the different voltages mentioned above. Data that was recorded over a minimum of 1 min was considered for the data analysis. The following formula was used in the Clampfit v10.3 software for $\mathrm{P}_{\mathrm{o}}$ calculation.

$$
\mathrm{P}_{\mathrm{o}}=\frac{\mathrm{t}_{\mathrm{o}}}{\mathrm{T}}
$$

Here, $P_{o}$ is the probability of channel being in the open state, $t_{o}$ is the total time that the channel is found in the open state and $\mathrm{T}$ is the total observation time. The results are presented in Figure S11 of the main text. 
Table S1. List of peptides described in this study with the observed mass.

\begin{tabular}{|c|c|c|c|}
\hline \multirow{2}{*}{$\begin{array}{l}\text { Sample } \\
\text { code }\end{array}$} & \multirow[t]{2}{*}{ Peptide Sequence $^{\$}$} & \multicolumn{2}{|c|}{ Molecular Weight (Da) } \\
\hline & & Expected & $\begin{array}{l}\text { Observed } \\
\text { (species) }\end{array}$ \\
\hline TM1 \# & KIRETLYYVGTLVPGILGIALIWGGIDA & 2999.711 & $3000.830 \quad\left(\mathrm{H}^{+}\right)$ \\
\hline $\mathrm{TM}^{\mathrm{PG} \#}$ & KIRETLYYVGTLVPGILGIALIWGGIDA & 2999.711 & $2999.993\left(\mathrm{H}^{+}\right)$ \\
\hline TM1 ${ }^{\text {UG \# }}$ & KIRETLYYVGTLVUGILGIALIWGGIDA & 2988.695 & $2989.348 \quad\left(\mathrm{H}^{+}\right)$ \\
\hline tTM1 & ADIETLYYVGTLVPGILGIALIWGGRIK & 2999.711 & $1501.1(2 \mathrm{H})^{2+}$ \\
\hline $\operatorname{tTM}^{\mathrm{A}}$ & ADAETLYYVGTLVPGILGIALIWGGRIK & 2957.664 & $1480.1(2 \mathrm{H})^{2+}$ \\
\hline $\operatorname{tTM} 1^{I}$ & IDIETLYYVGTLVPGILGIALIWGGRIK & 3041.758 & $1522.1(2 \mathrm{H})^{2+}$ \\
\hline $\operatorname{trTM} 1^{27}$ & DIETLYYVGTLVPGILGIALIWGGRIK & 2928.674 & $1465.6(2 \mathrm{H})^{2+}$ \\
\hline $\operatorname{trTM} 1^{26}$ & IETLYYVGTLVPGILGIALIWGGRIK & 2813.647 & $1408.1(2 \mathrm{H})^{2+}$ \\
\hline sTM1 & ADIGGWIYVGTLVPGILGIALYLTERIK & 2999.711 & $3001.553\left(\mathrm{H}^{+}\right)$ \\
\hline sTM1 $1^{\mathrm{pG}}$ & ADIGGWIYVGTLVPGILGIALYLTERIK & 2999.711 & $3001.679\left(\mathrm{H}^{+}\right)$ \\
\hline rTM1 & ADIGGWILAIGLIPGVLTGVYYLTERIK & 2999.711 & $3000.837 \quad\left(\mathrm{H}^{+}\right)$ \\
\hline rTM1 $1^{\mathrm{pG}}$ & ADIGGWILAIGLIpGVLTGVYYLTERIK & 2999.711 & $3000.991 \quad\left(\mathrm{H}^{+}\right)$ \\
\hline$r \mathrm{TM} 1^{\mathrm{GP}}$ & ADIGGWILAIGLIGPVLTGVYYLTERIK & 2999.711 & $3000.781 \quad\left(\mathrm{H}^{+}\right)$ \\
\hline$r T M 1^{\mathrm{GP}}$ & ADIGGWILAIGLIGPVLTGVYYLTERIK & 2999.711 & $3000.921 \quad\left(\mathrm{H}^{+}\right)$ \\
\hline \multicolumn{4}{|c|}{ 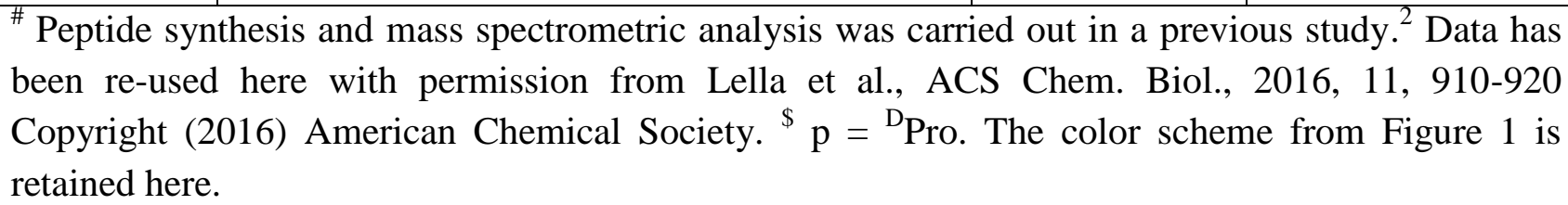 } \\
\hline
\end{tabular}




\section{Supporting Figures}
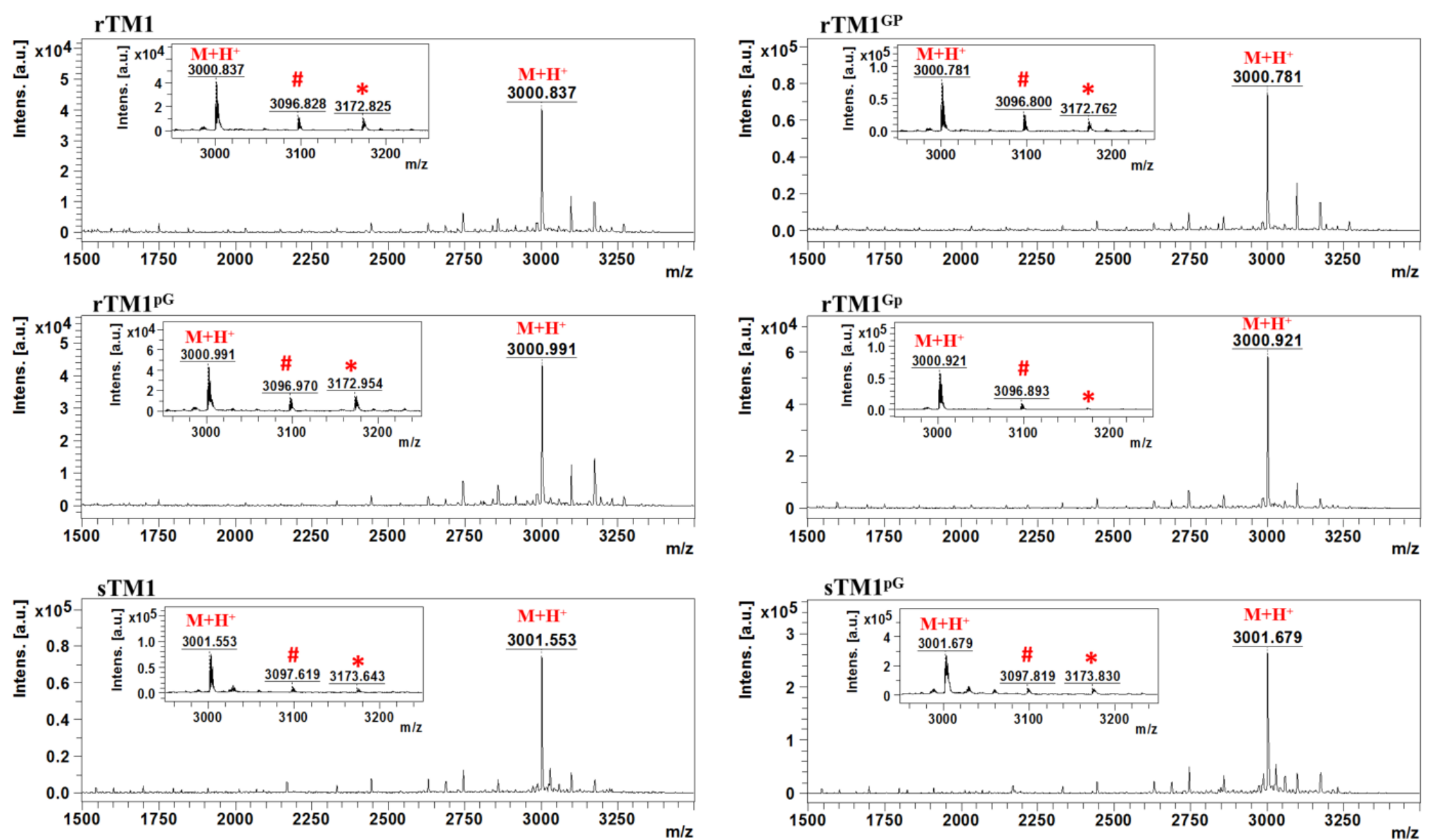

Figure S1a: Mass spectrometric analysis of rTM1, rTM1 ${ }^{\mathrm{pG}}$, rTM1 ${ }^{\mathrm{GP}}, \mathrm{rTM} 1^{\mathrm{Gp}}$, sTM1 and sTM1 ${ }^{\mathrm{pG}}$ recorded on MALDI-ToF. Each graph shows the complete spectrum, with the major peak corresponding to the $\mathrm{H}^{+}$adduct of the expected peptide molecular weight. The inset shows the $\mathrm{H}^{+}$, TFA (\#) and EDT/TFA cyclic product $(*)$ adducts. 

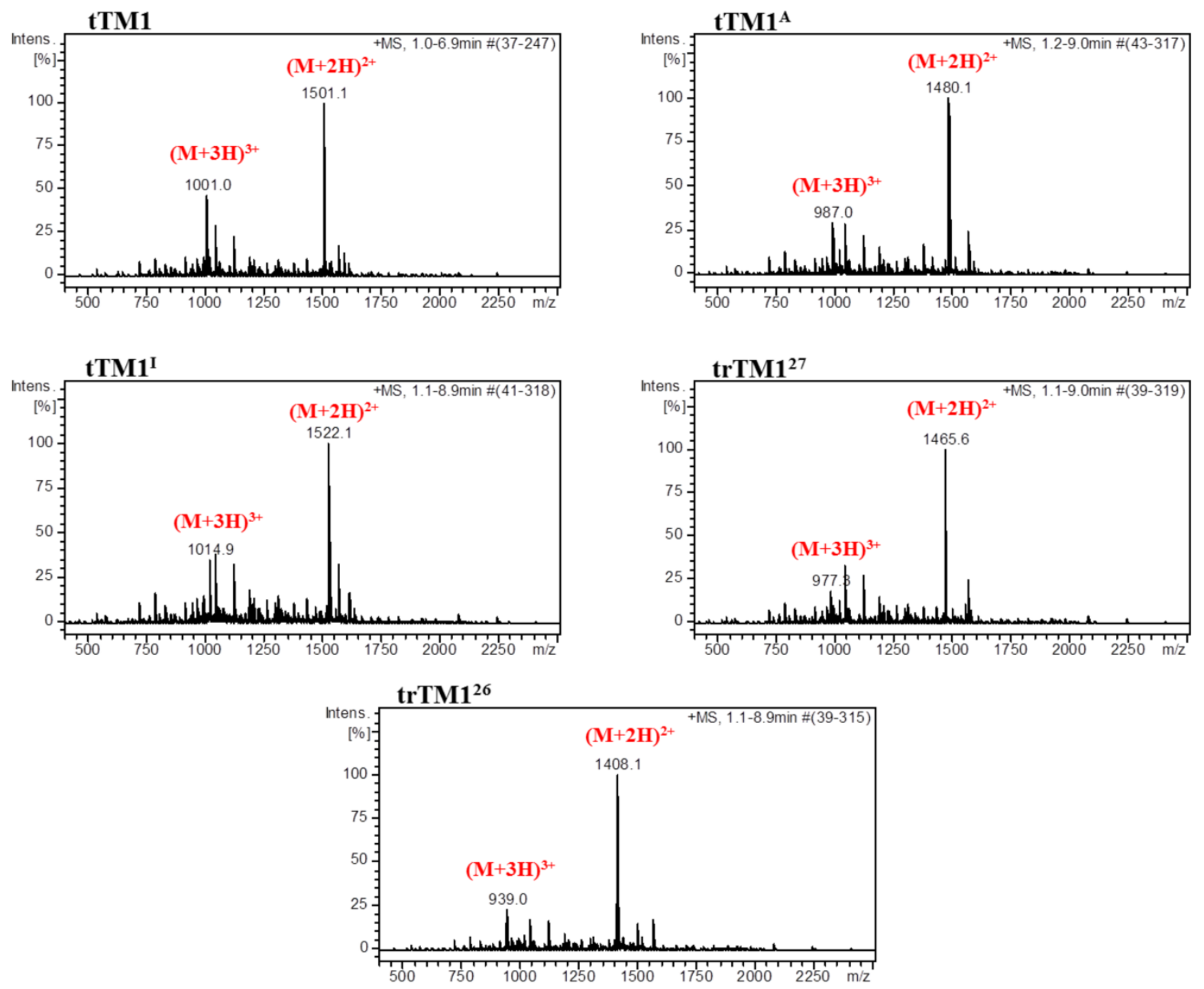

Figure S1b: Mass spectrometric analysis of tTM1, tTM1 ${ }^{\mathrm{A}}, \mathrm{tTM} 1^{\mathrm{I}}, \operatorname{trTM} 1^{27}$ and $\operatorname{trTM} 1^{26}$ recorded on an Esquire 3000 Plus ion trap mass spectrometer. Each graph shows the complete spectrum, with the major peak corresponding to the $2 \mathrm{H}^{+}$and $3 \mathrm{H}^{+}$adduct of the expected peptide molecular weight. 
A

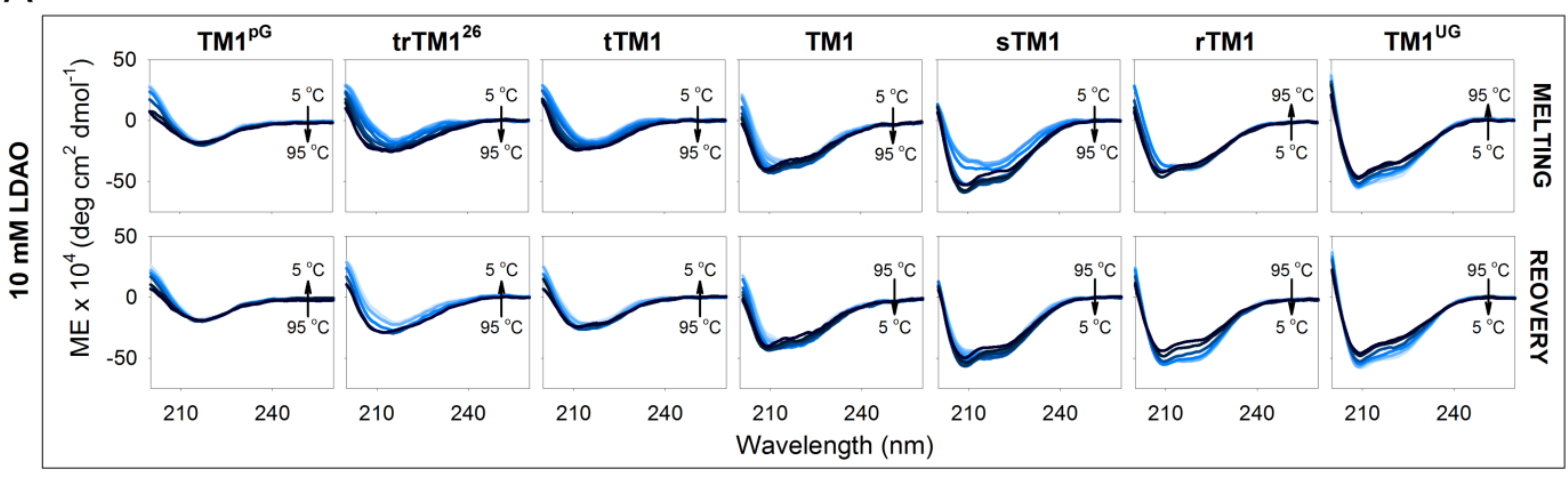

B

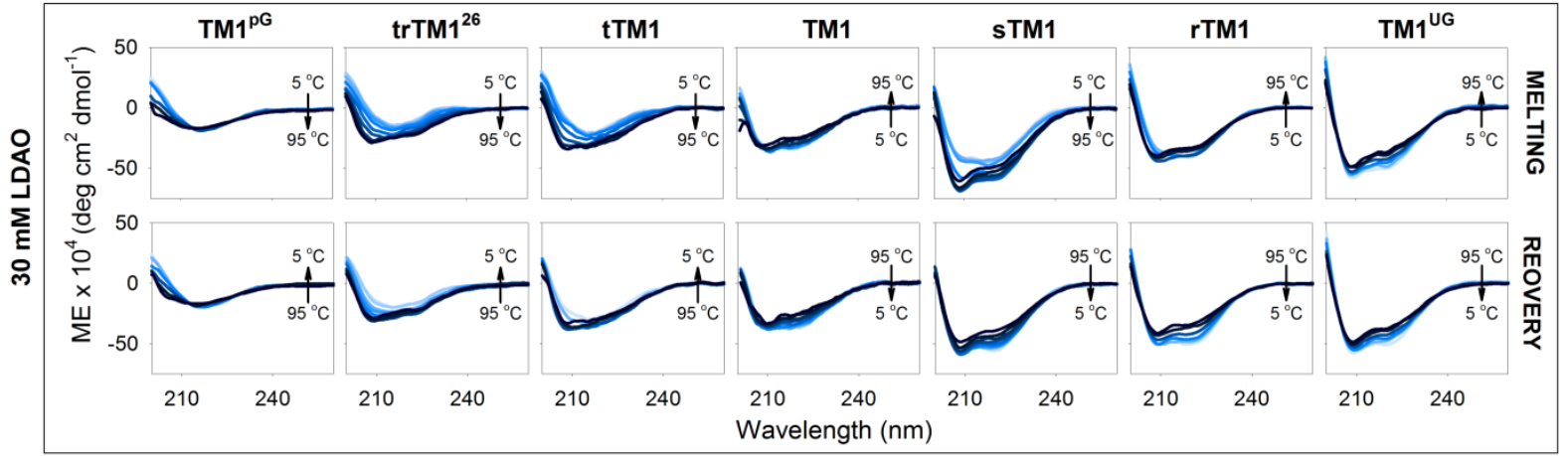

C

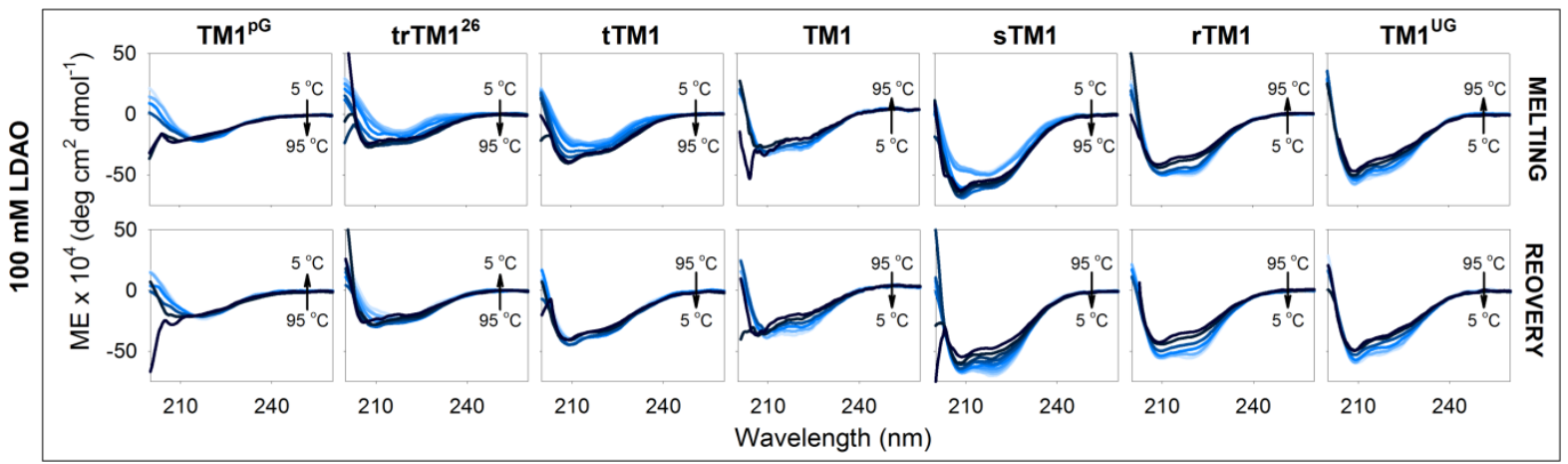

Figure S2. Representative CD wavelength scans of thermal melting (5-95 $\left.{ }^{\circ} \mathrm{C}\right)$ and recovery $(95-5$ ${ }^{\circ} \mathrm{C}$ ) for all the engineered peptides in $10 \mathrm{mM}$, (A) $30 \mathrm{mM}(\mathrm{B})$ and $100 \mathrm{mM} \mathrm{LDAO}(\mathrm{C})$. Both TM1 ${ }^{\mathrm{pG}}$ and $\mathrm{TM} 1^{\mathrm{UG}}$ shown loss and gain of their respective secondary structures upon melting and recovery, but no structural interconversion is observed in all detergent conditions. ${ }^{2}$ TM1 shows the reversible $\beta$-hairpin $\leftrightarrow \alpha$-helix transition in all detergent conditions. ${ }^{1}$ trTM1 ${ }^{26}$, tTM1, sTM1 and rTM1 show the irreversible structural transition from $\beta$-hairpin to $\alpha$-helix upon melting, with the $\alpha$-helix getting stabilized upon cooling. This progression is more rapid with increasing detergent concentration and increasing amino acid swap between the strands (tTM1 to rTM1). Light blue colors denote the low temperatures (starting at $5{ }^{\circ} \mathrm{C}$ ) and dark blue colors denote the higher temperature (ending at $95{ }^{\circ} \mathrm{C}$ ). Data obtained at every $25{ }^{\circ} \mathrm{C}$ are shown in each plot. ME: Molar ellipticity in units of deg $\mathrm{cm}^{2}$ $\mathrm{dmol}^{-1}$. TM1 ${ }^{\mathrm{pG}}$ and TM1 data has been reproduced from reference ${ }^{1}$ with permission from The Royal Society of Chemistry. TM1 ${ }^{\mathrm{UG}}$ data has been reprinted with permission from Lella et al., ACS Chem. Biol., 2016, 11, 910-920. Copyright (2016) American Chemical Society. 
A

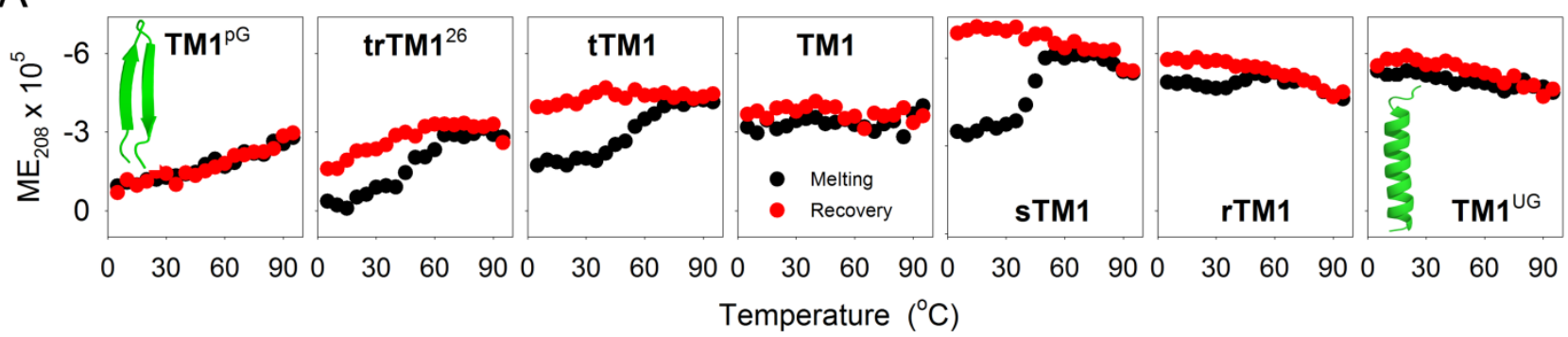

B

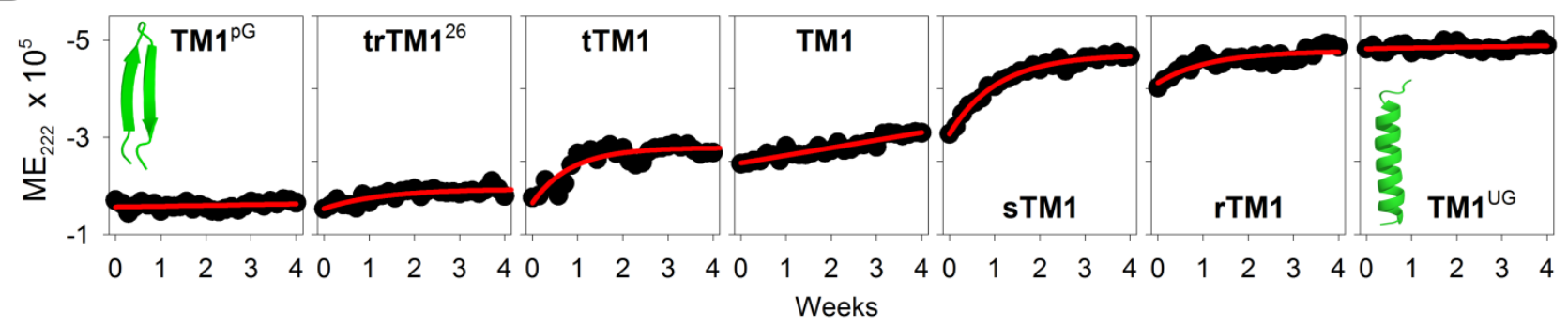

Figure S3. Reverse engineered peptides show an increase in helicity with increasing temperature (A) and prolonged incubation (B) in $100 \mathrm{mM}$ LDAO. Panel A shows the $\mathrm{ME}_{208}$ values for all chimeric peptides plotted as a function of temperature. An increase in $\mathrm{ME}_{208}$ suggests the gain of structure (helicity) upon melting $\left(5-95^{\circ} \mathrm{C}\right)$, which is stabilized upon thermal recovery $\left(95-5^{\circ} \mathrm{C}\right)$. A more pronounced change is observed in the following order: $\mathrm{sTM} 1>\mathrm{rTM} 1>\operatorname{tTM} 1>\operatorname{trTM} 1^{26}$. A complete reversibility of the denaturation profile is observed only in the case of $\mathrm{TM}{ }^{\mathrm{pG}}$, TM1 and $\mathrm{TM} 1^{\mathrm{UG}}$. Black circle denotes the data from melting and red circle denotes the recovery measurements. Panel B shows the time-dependent structural change observed for all peptides from time 0 to 28 days ( 4 weeks).The $\mathrm{ME}_{222}$ values are plotted to check the overall structural change with time for $30 \mathrm{mM}$ LDAO (Figure 2C) and $100 \mathrm{mM}$ LDAO (panel B), and suggest that increasing helicity is observed upon strand reversal. All samples were incubated at $5{ }^{\circ} \mathrm{C}$, and the data were acquired at $25^{\circ} \mathrm{C}$. Fits (solid lines) highlight the trend in the datasets. ME: Molar ellipticity in units of deg $\mathrm{cm}^{2} \mathrm{dmol}^{-1}$. 


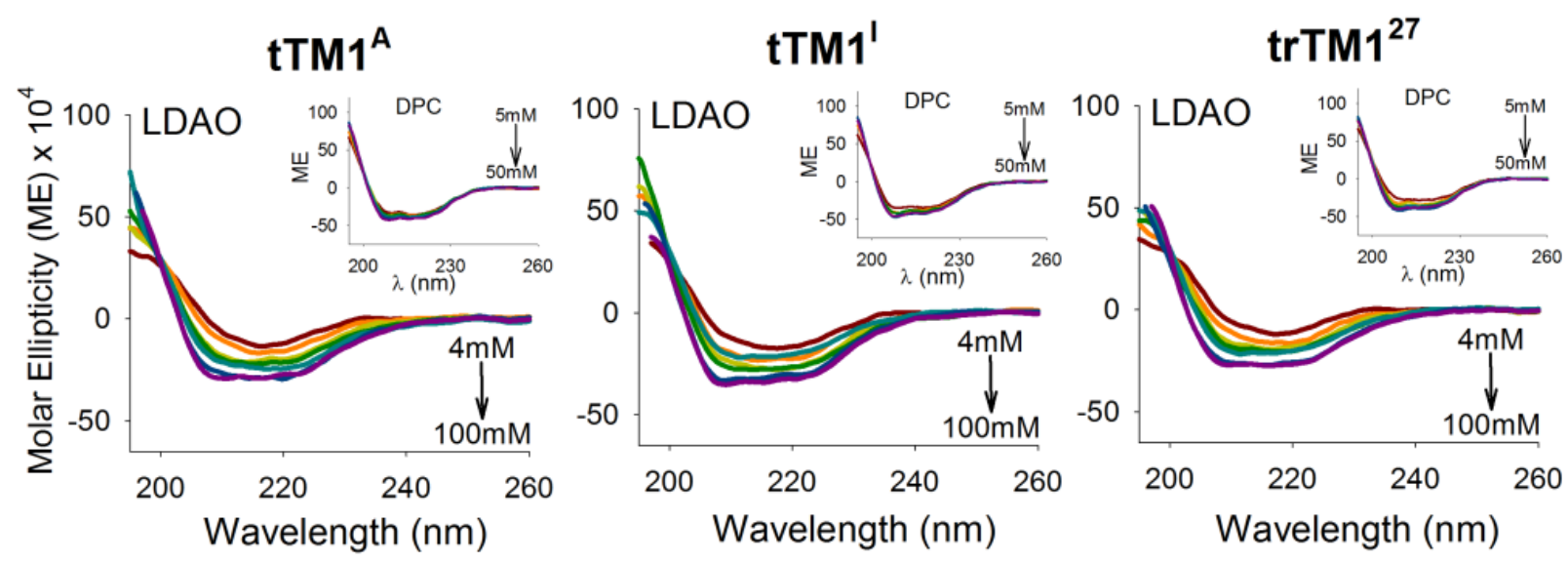

Figure S4a. Far-UV CD spectral analysis of $\mathrm{tTM}^{\mathrm{A}}$, $\mathrm{tTM}^{\mathrm{I}}$ and $\operatorname{trTM}^{27}$ in 4-100 mM LDAO (main graph) and 5-50 $\mathrm{mM} \mathrm{DPC} \mathrm{(inset).} \mathrm{Shown} \mathrm{here} \mathrm{are} \mathrm{the} \mathrm{spectra} \mathrm{recorded} \mathrm{after} 21$ days of incubation of all refolded peptides at $4{ }^{\circ} \mathrm{C}$. Spectra were acquired at $25{ }^{\circ} \mathrm{C}$. An increase in the peptide helicity is observed with an increase in the LDAO or DPC concentration (DPC data is provided in the inset graph). Ala was introduced at the $3^{\text {rd }}$ position $\left(\mathrm{A}^{3}\right.$; see Figure $1 \mathrm{~A}$ or Table $\mathrm{S} 1$ for the sequence) in $\mathrm{tTM}^{\mathrm{A}}$ peptide to improve the helicity; however, Ala did not show much effect on the helical content (compare tTM1 ${ }^{\mathrm{A}}$ and $\operatorname{trTM} 1^{27}$ ). Another mutant was made by placing Ile at the first position (tTM1 ${ }^{\mathrm{I}}$; see Figure $1 \mathrm{~A}$ or Table $\mathrm{S} 1$ for the sequence) by keeping in mind that increasing the $\beta$ branched residues and hydrophobicity could favor $\beta$-hairpin formation. However, the Ile-containing peptide retained helicity in LDAO and DPC, which suggest that Ile favors helix nucleation at the Nterminus. A terminal amino acid ( $\mathrm{A}^{1}$; see Figure $1 \mathrm{~A}$ or Table $\mathrm{S} 1$ for the sequence) truncation was made to generate $\operatorname{trTM} 1^{27}$ and to scrutinize whether the $\mathrm{N}$-terminal residue plays a role in the helix $\leftrightarrow$ hairpin conversion. This peptide showed less secondary structure content compared to the tTM1 peptide and more secondary structure content compared to trTM $1^{26}$, suggesting that the N-terminal residue might be important to induce helicity in TM1 peptides. However, the conformational reversibility (seen for TM1) was not observed. ME: Molar ellipticity in units of deg $\mathrm{cm}^{2} \mathrm{dmol}^{-1}$. 
A

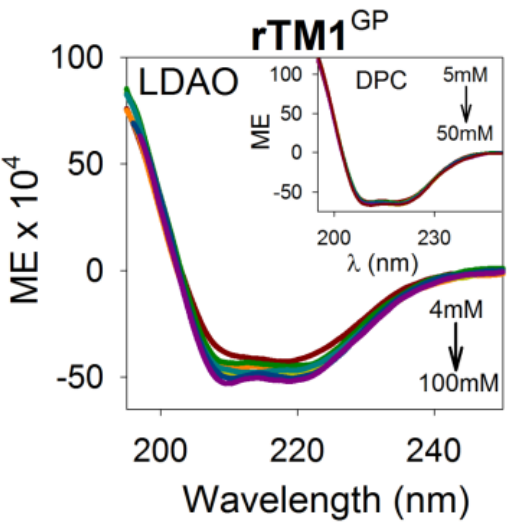

B

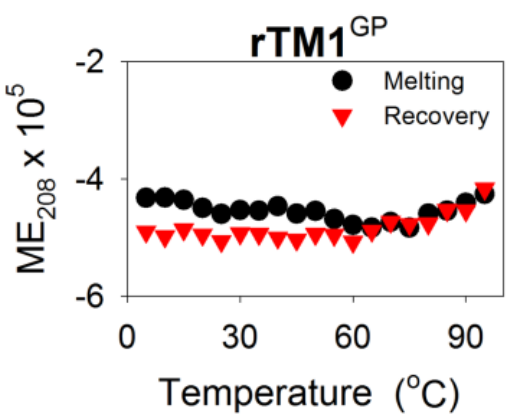

C

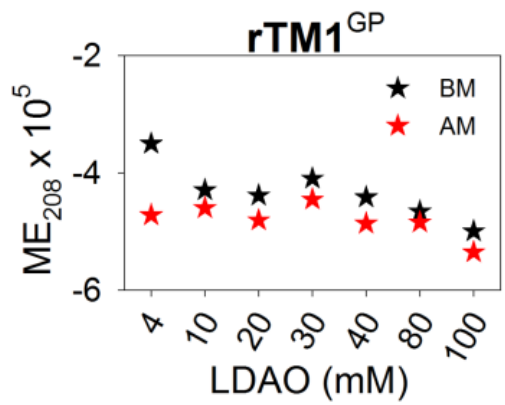

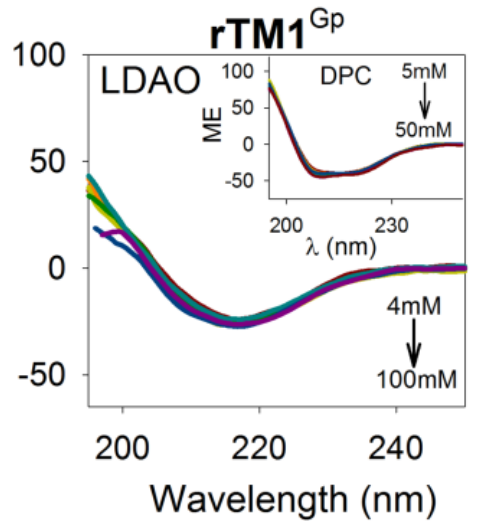
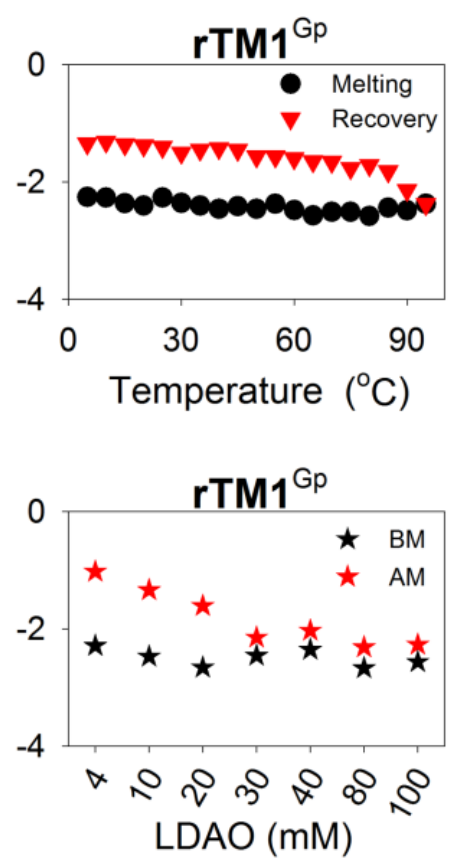

Figure S4b. Far-UV CD spectral analysis of Pro-Gly permutants of the rTM1 peptides. Shown here is data for $\mathrm{rTM}^{\mathrm{GP}}$ (left) and $\mathrm{rTM} 1^{\mathrm{Gp}}$ (right) in LDAO micelles. (A) rTM1 ${ }^{\mathrm{GP}}$ shows a characteristic spectrum of $\alpha$-helix in 4-100 mM LDAO (main graph) and 5-50 mM DPC (inset). rTM1 ${ }^{\text {Gp }}$ shows a $\beta$-sheet - like spectrum in all the LDAO concentrations used here. We obtain a CD spectrum of $\alpha$ helix in DPC (inset), as seen in the case of $\mathrm{rTM}^{\mathrm{pG}}$ (Figure S4c). A rainbow color scheme is maintained in each spectrum, with red and violet corresponding to the lowest and highest DPRs. All data are presented as molar ellipticity (ME) values with units of deg $\mathrm{cm}^{2} \mathrm{dmol}^{-1}$. (B) Thermal melting data of both peptides in $10 \mathrm{mM}$ LDAO is shown here as ME values monitored at $208 \mathrm{~nm}$ $\left(\mathrm{ME}_{208}\right)$. The data reveals that $\mathrm{rTM}^{\mathrm{GP}}$ (left) undergoes a marginal loss of secondary structure in thermal melting measurements from $5-95{ }^{\circ} \mathrm{C}$ (black filled circles) and a moderate gain of secondary structure upon recovery from $95-5{ }^{\circ} \mathrm{C}$ (red filled inverted triangles). For rTM1 ${ }^{\mathrm{Gp}}$ peptide (right), which adopts a $\beta$-sheet - like structure, we observe no change in the CD spectrum upon melting, but we observed precipitation of the peptide upon cooling. This could be because of ${ }^{\mathrm{D}}$ Pro, which could lead to peptide aggregation when the structure is disrupted by heating. (C) Before and after melting (BM and AM, respectively) ellipticity data at $208 \mathrm{~nm}\left(\mathrm{ME}_{208}\right)$ were plotted against the LDAO gradient. The $\mathrm{ME}_{208}$ values suggest that $\mathrm{rTM}^{\mathrm{GP}}$ gains helicity with increase in LDAO, and retain the structure after thermal denaturation and recovery. rTM $^{\mathrm{Gp}}$ loses $\beta$-sheet - like structure after thermal melting, particularly in LDAO concentrations $<30 \mathrm{mM}$. ME is in units of deg $\mathrm{cm}^{2} \mathrm{dmol}^{-1}$. 

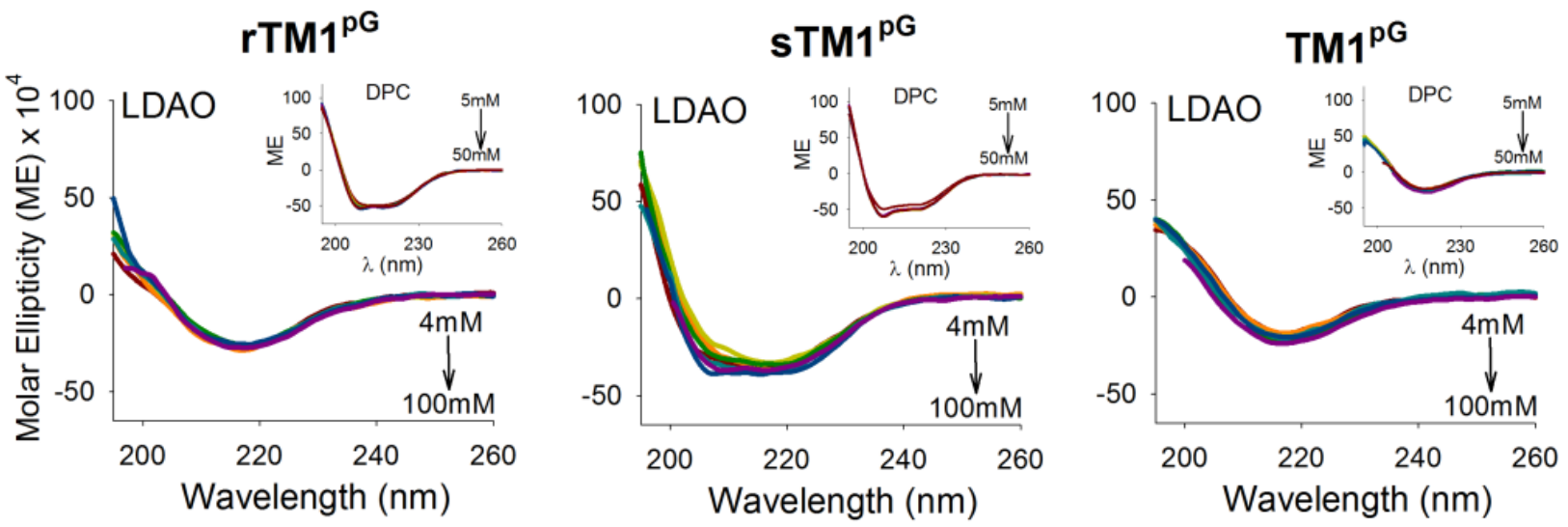

Figure S4c. Far-UV CD spectral analysis of $\mathrm{rTM}^{\mathrm{pG}}{ }^{\mathrm{sTM}} 1^{\mathrm{pG}}$ and $\mathrm{TM} 1^{\mathrm{pG}}$ in 4-100 mM LDAO (main graph) and 5-50 mM DPC (inset). We incorporated a D-proline at the $i+1$ position of the ${ }^{\mathrm{D}}$ Pro-Gly $\beta$-turn, based on previous reports. ${ }^{1} \mathrm{rTM}^{\mathrm{pG}}$ and $\mathrm{TM}^{\mathrm{pG}}$ shows a $\mathrm{CD}$ spectrum characteristic of $\beta$-hairpin in the entire LDAO concentration gradient, but $\mathrm{sTM} 1^{\mathrm{pG}}$ shows a mixed population of $\alpha$-helix and $\beta$-hairpin. DPC has the tendency to favor helicity, and the reverse chimeric peptides $\left(\mathrm{rTM} 1^{\mathrm{pG}}\right.$ and $\mathrm{sTM} 1^{\mathrm{pG}}$ ) showed more pronounced helicity in this detergent. The effect of D-proline in maintaining $\beta$-turn registry is overcome in DPC samples for these two peptides, and a characteristic CD spectrum of $\alpha$-helix is seen. This is, however, not true in the case of $\mathrm{TM}^{\mathrm{pG}}$, where we obtain a $\beta$-hairpin - like CD in both LDAO and DPC. ME: Molar ellipticity in units of deg $\mathrm{cm}^{2} \mathrm{dmol}^{-1}$. $\mathrm{TM}^{\mathrm{pG}}$ data has been reproduced from ${ }^{2}$ with permission from The Royal Society of Chemistry. 


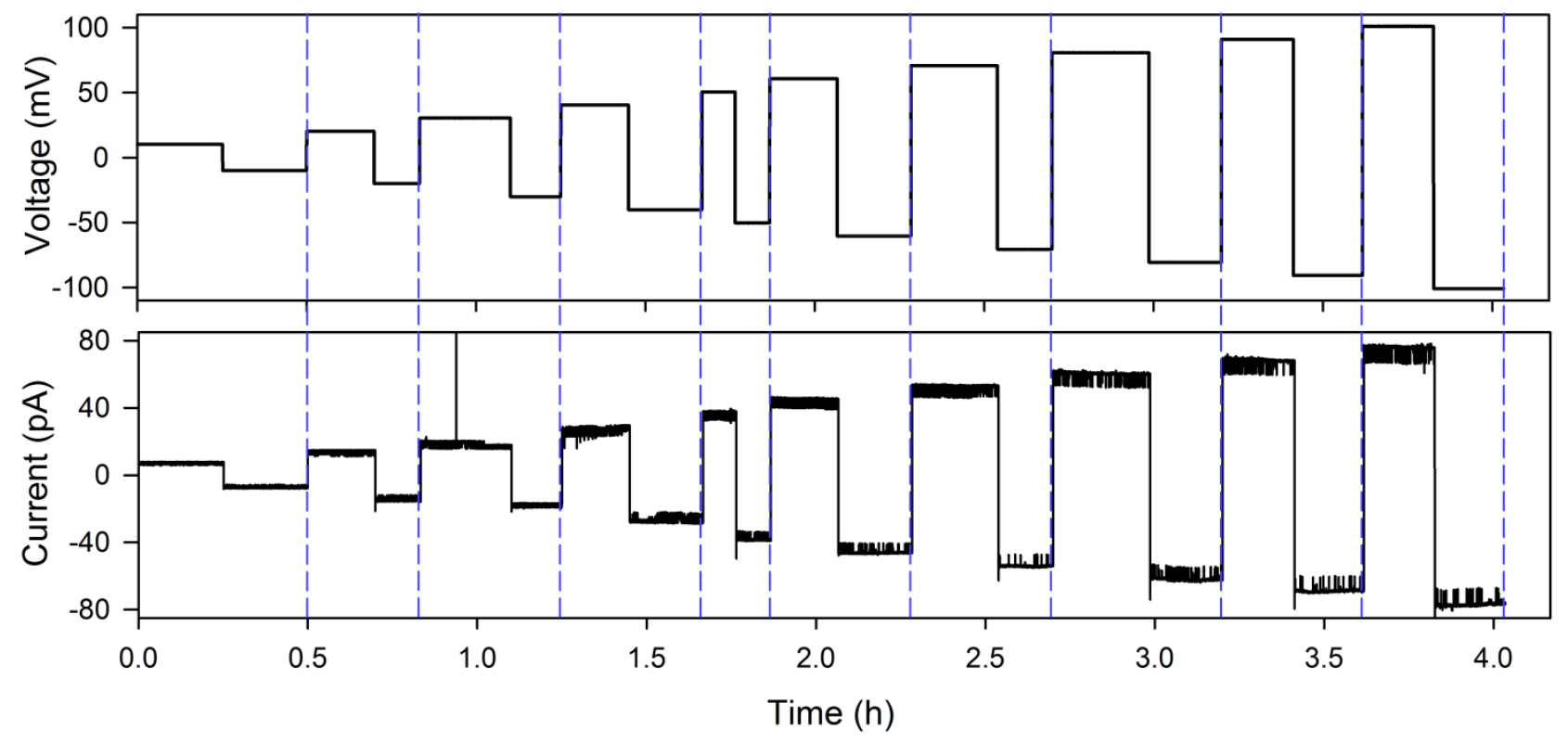

Figure S5. rTM1 peptide shows stable ion channel activity for hours. Holding voltage measurements for rTM1 recorded at every voltage from $-100 \mathrm{mV}$ to $+100 \mathrm{mV}$, in steps of $10 \mathrm{mV}$. Shown here is a single experiment, wherein the peptide is added to the planar bilayer set-up at +10 $\mathrm{mV}$ (time 0 ), and the data is acquired at various holding voltages. The top panel shows the voltage $(\mathrm{mV})$ applied to the membrane with respect to time, and the bottom panel shows the measured current (pA) at the applied voltage. Data were acquired every $0.1 \mathrm{~ms}$ for the different voltages, and stored as separate files (demarcated by the blue dashed lines). The data points in each file are compressed and shown here as a single continuous recording. The data suggests that rTM1 peptide can show ion channel activity for several hours after stable ion channel formation in the DiPhPC membrane. 

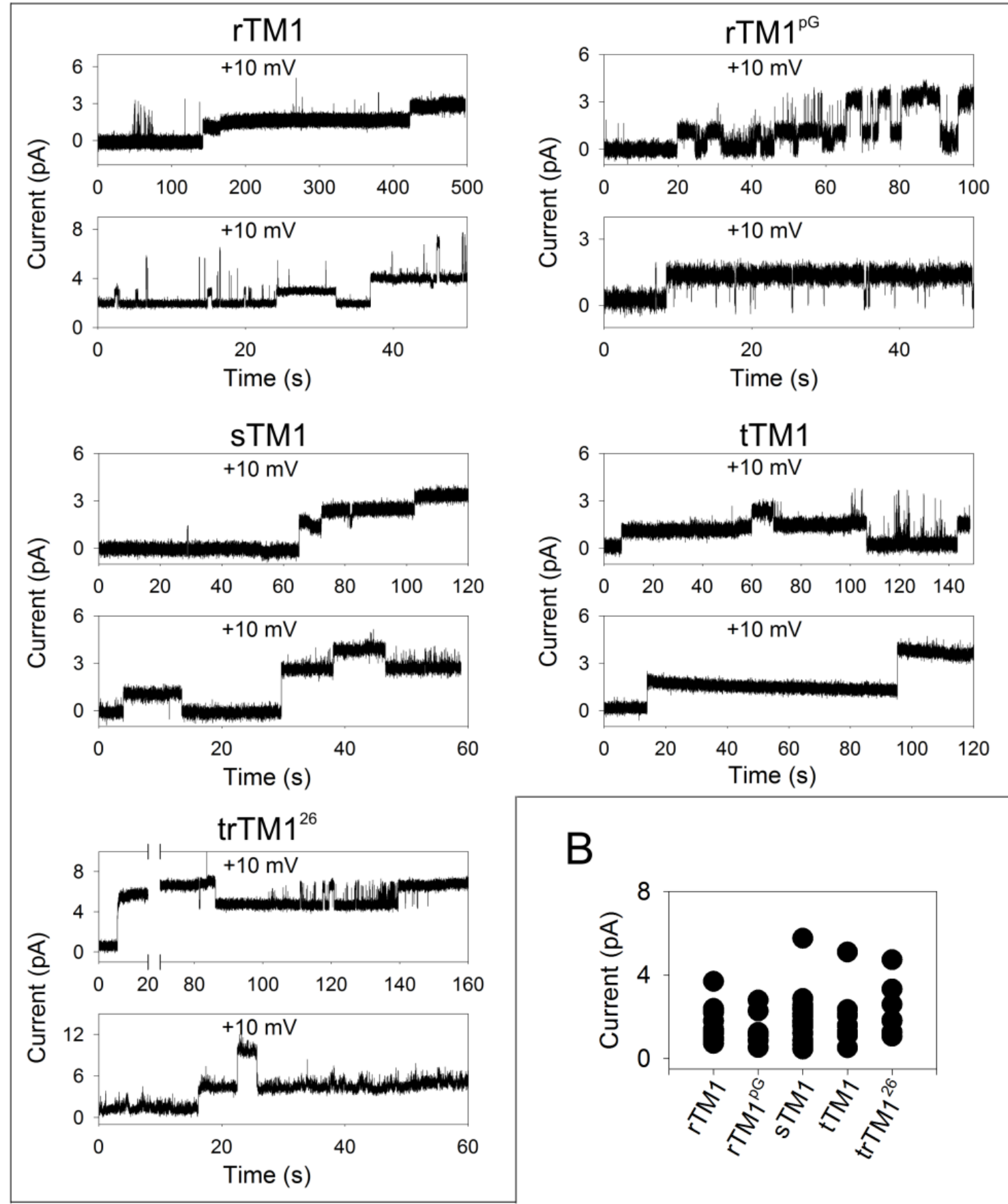

B

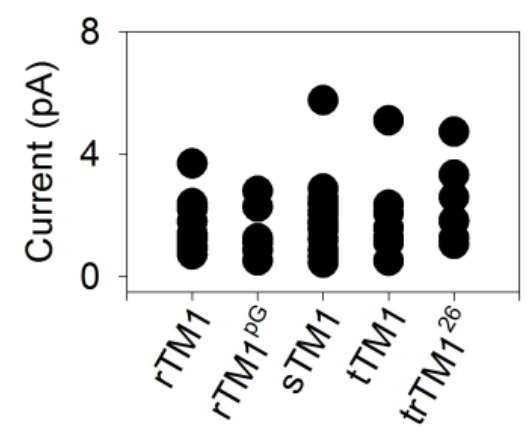

Figure S6. Insertion of the engineered peptides in lipidic membranes. (A) Representative data for rTM1, rTM1 ${ }^{\mathrm{pG}}$, sTM1, tTM1 and trTM1 ${ }^{26}$ at $+10 \mathrm{mV}$. The refolded peptide was added into the $c$ is chamber of the planar bilayer set-up. (A) The initial step of peptide insertion in the membrane causes shows that currents between $\sim 0.6-4.0 \mathrm{pA}$ can be observed for the various step-wise insertion events for all chimeric peptides (summarized in (B)). Ordered oligomerization and assembly of the peptide in the membrane can lead to effective ion channels (shown in Figure S7). (B) Scatter plot depicting the observed current (in pA) for all the events during initial peptide insertion in the membrane. The plot shows that all the peptides behave in a similar manner. 


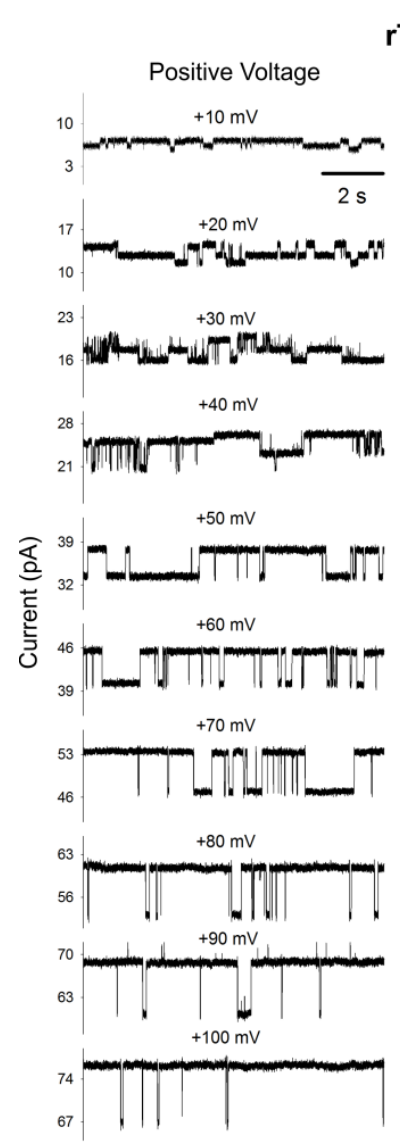

rTM1
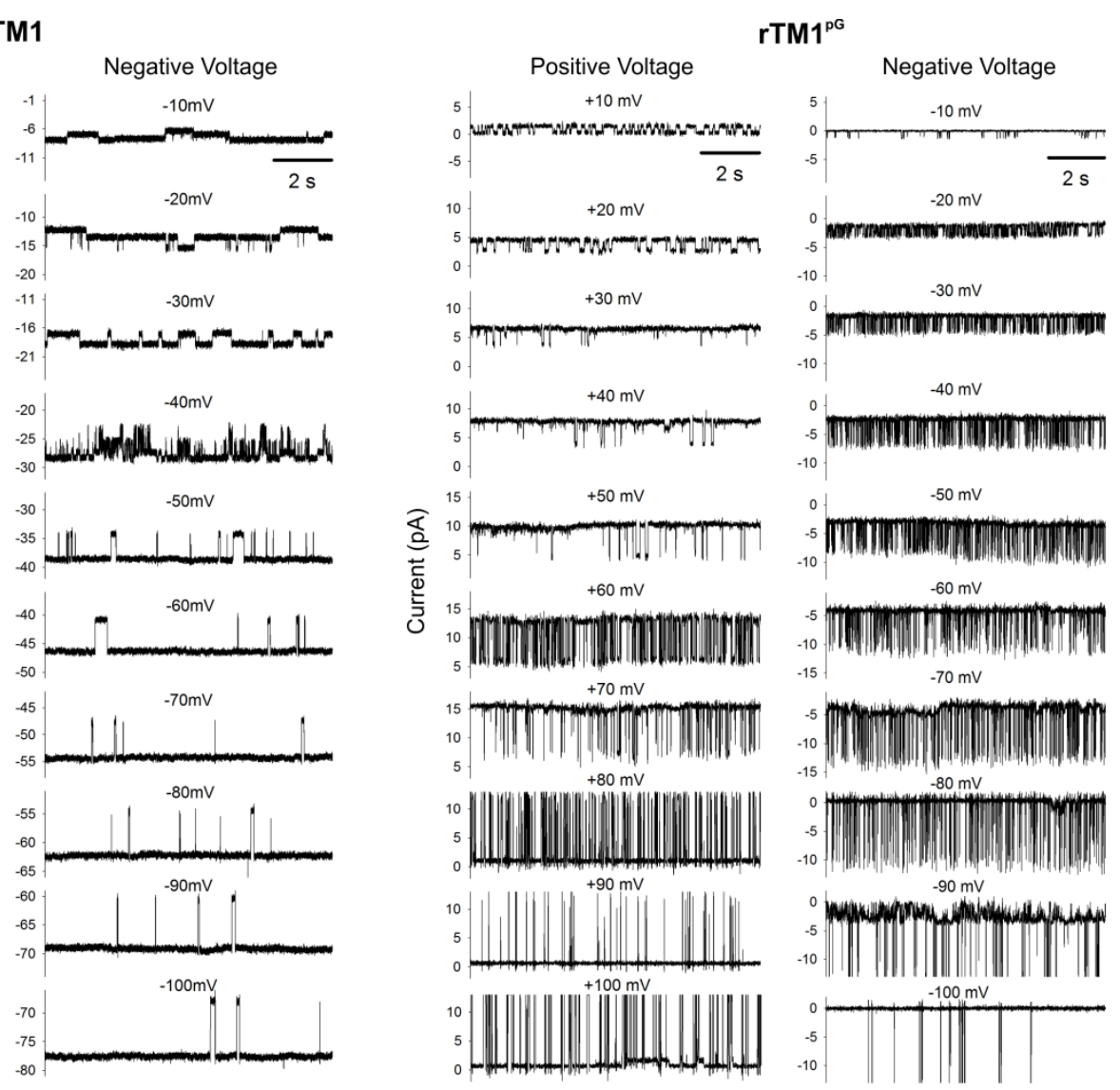

Figure S7a. Representative graphs of holding voltage measurements for rTM1 (left two panels) and $\mathrm{rTM}^{\mathrm{pG}}$ (right two panels) at every voltage from $-100 \mathrm{mV}$ to $+100 \mathrm{mV}$, in steps of $10 \mathrm{mV}$. The rTM1 peptide shows the formation of stable channels that show longer dwell time in the open state, at higher voltages $(> \pm 50 \mathrm{mV})$. On the other hand, changing the chirality of proline ( ${ }^{\mathrm{L}}$ Pro to ${ }^{\mathrm{D}}$ Pro) in $\mathrm{rTM}^{\mathrm{pG}}$ shows channels with shorter dwell time in the open state at higher voltages. Hence, rTM1 shows a preference for an open channel state at higher voltages, while rTM1 ${ }^{\mathrm{pG}}$ preferentially exists in the low conductance state at high voltages. 

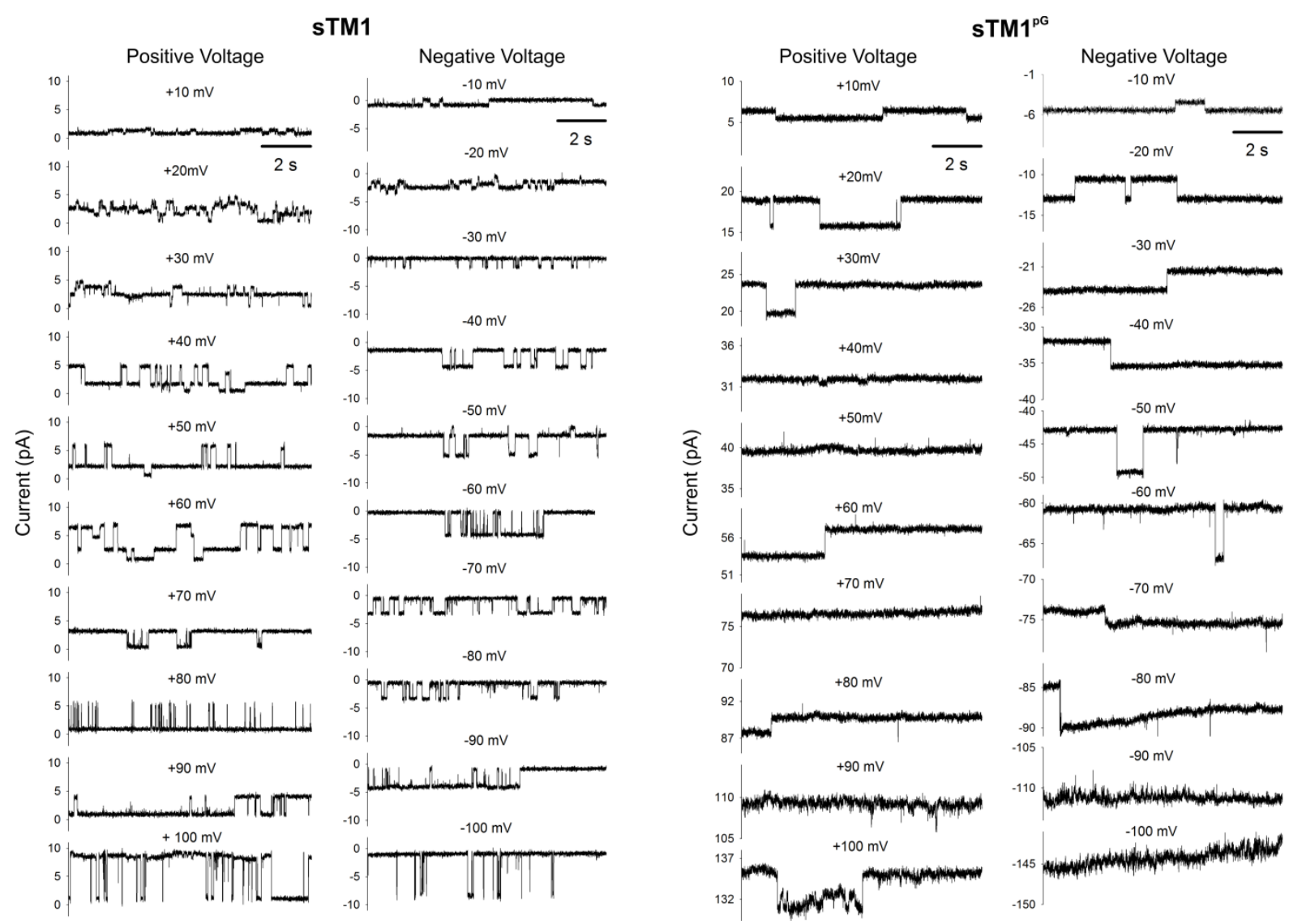

Figure S7b. Representative graphs of holding voltage measurements for sTM1 (left two panels) and $\mathrm{sTM}^{\mathrm{pG}}$ (right two panels) at every voltage from $-100 \mathrm{mV}$ to $+100 \mathrm{mV}$, in steps of $10 \mathrm{mV}$. sTM1 peptide shows a similar behavior as that of rTM1 at lower voltages. As we increase the voltage towards $\pm 100 \mathrm{mV}$, the channel dwell time in the open state is shortened, as it switches to the low conductance state. Changing the chirality of proline in the sTM1 ${ }^{\mathrm{pG}}$ peptide causes an increase in the dwell time of the channel in both open and low conductance states, with membrane destabilization and noisy data at voltages higher than $\pm 80 \mathrm{mV}$. 

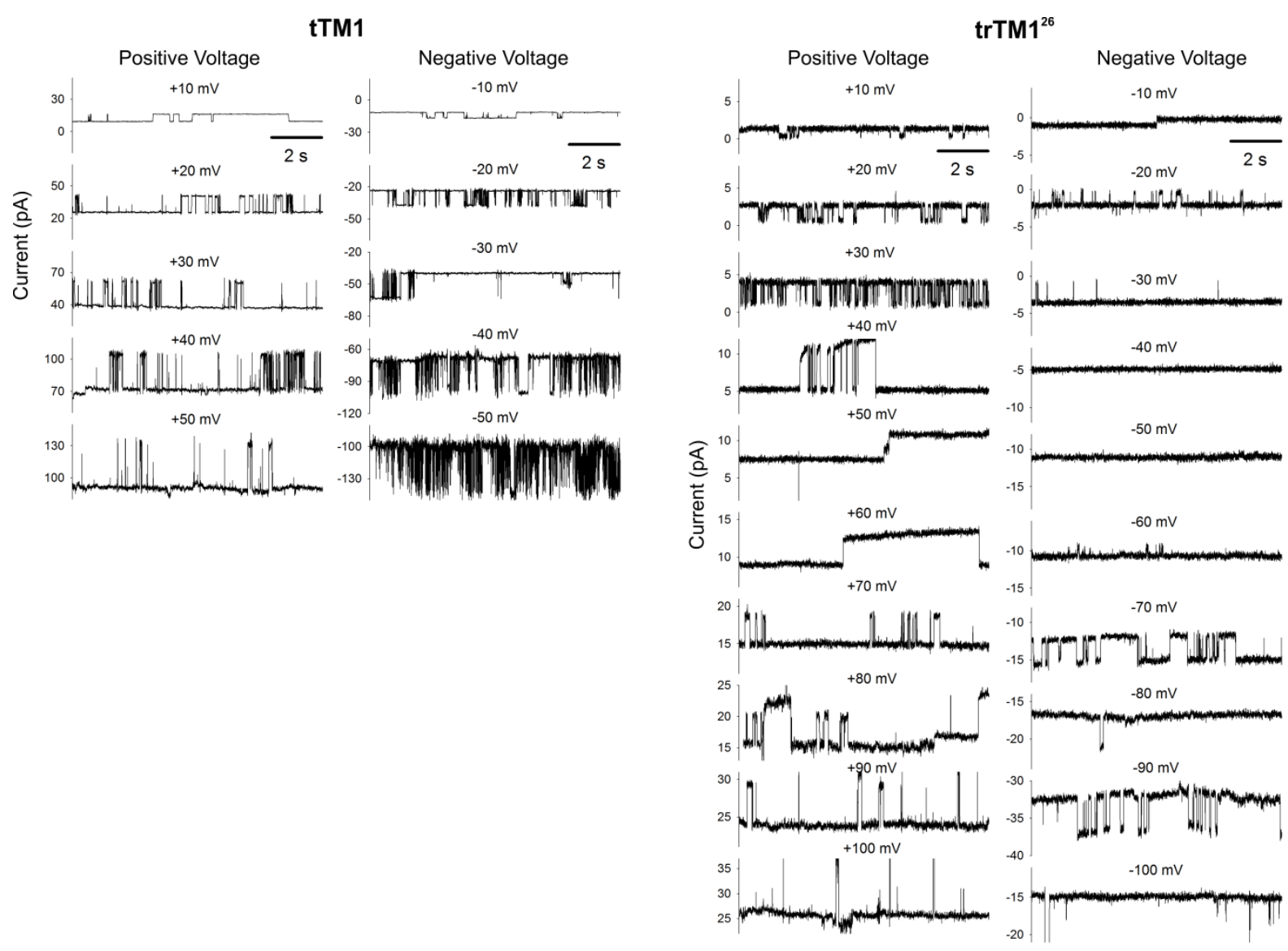

Figure S7c. Representative graphs of holding voltage measurements for tTM1 (left two panels) and $\operatorname{trTM}^{26}$ (right two panels) at every voltage from $-100 \mathrm{mV}$ to $+100 \mathrm{mV}$, in steps of $10 \mathrm{mV}$. tTM1 and $\operatorname{trTM} 1^{26}$ peptides exhibit both ion channel-like activity and can disrupt the membrane, particularly at voltages $> \pm 50 \mathrm{mV}$. Representative instances for trTM1 ${ }^{26}$ where we could record channel-like behavior, prior to membrane disruption, are shown here. 

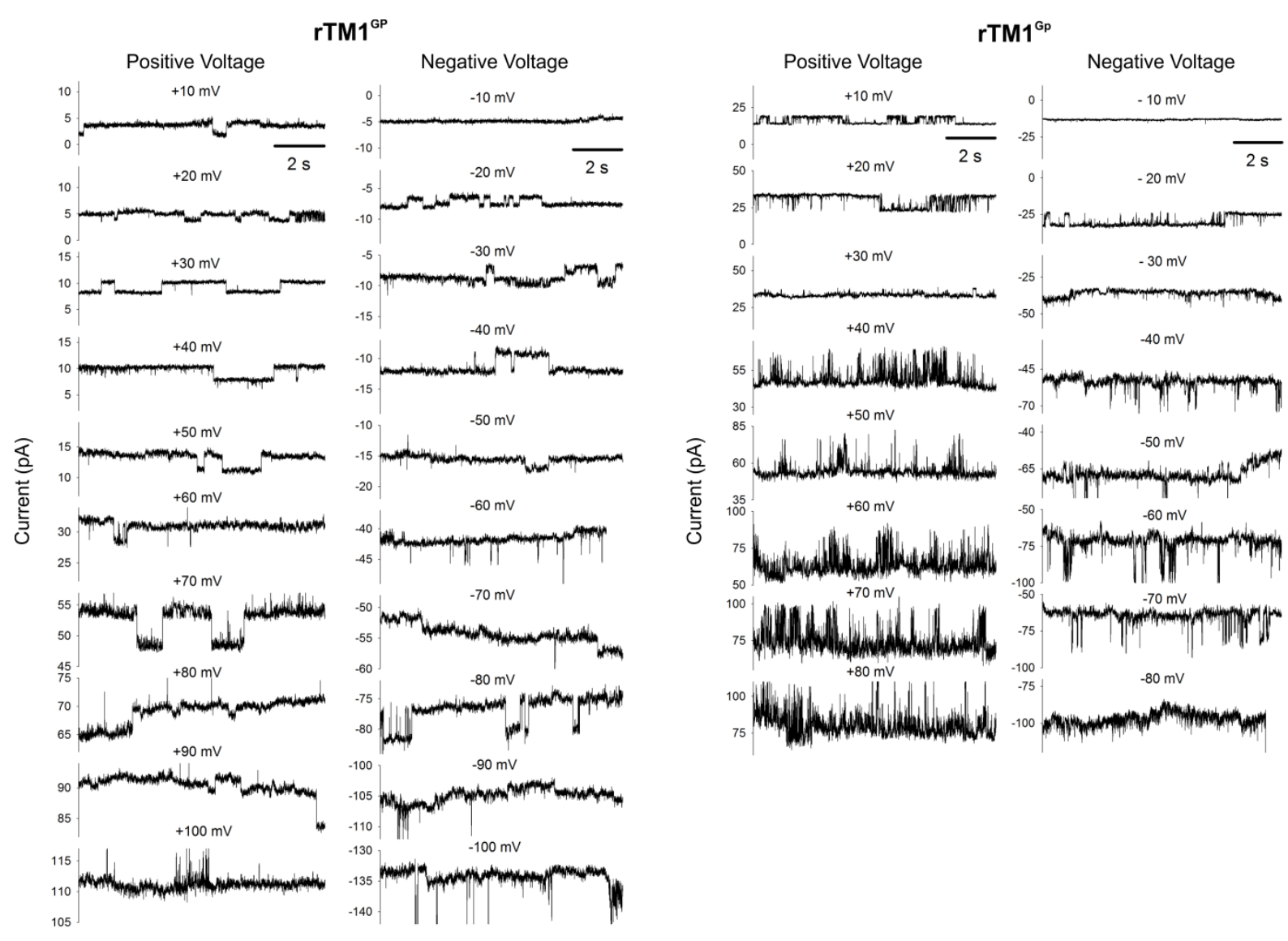

Figure S7d. Representative graphs of holding voltage measurements for rTM1 ${ }^{\text {GP }}$ (left two panels) and rTM $^{\mathrm{Gp}}$ (right two panels) at every voltage from $-100 \mathrm{mV}$ to $+100 \mathrm{mV}$, in steps of $10 \mathrm{mV}$. Change in the position of proline (compare rTM $^{\text {GP }}$ and rTM1 in Figure S7a) as well as a change in the chirality (compare $\mathrm{rTM} 1^{\mathrm{GP}}$ with $\mathrm{rTM} 1^{\mathrm{Gp}}$, this figure) gives rise to poorly formed noisy channels. Further, we observe that the DiPhPC membrane loses stability at higher voltages after these peptides are incorporated. For rTM $^{\mathrm{Gp}}$ peptide, we were able to obtain PLB measurements till \pm 80 $\mathrm{mV}$; higher voltages provided noisy channels and caused membrane disruption. 

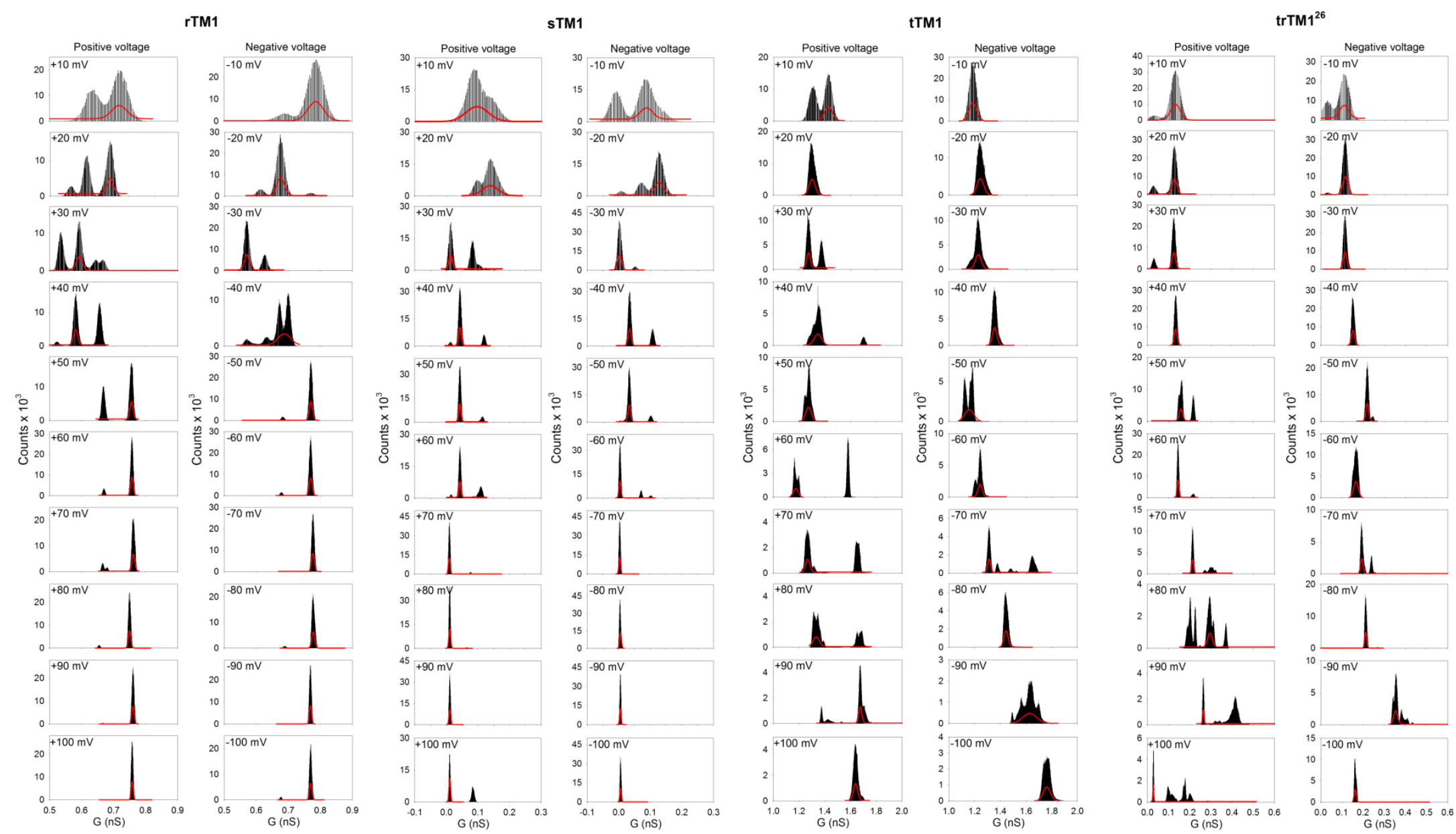

Figure S8a. Representative graphs of conductance (G, in units of nS) shown as black bars, achieved from holding voltage data for rTM1, sTM1, tTM1 and $\operatorname{trTM} 1^{26}$. The histograms were fitted to a Gaussian distribution in peak function (fits shown as red lines) and the maximum observed states were derived. A minimum of three such recordings were used to derive $G / G_{10}$ plots shown in Figure $S 8 b$. 


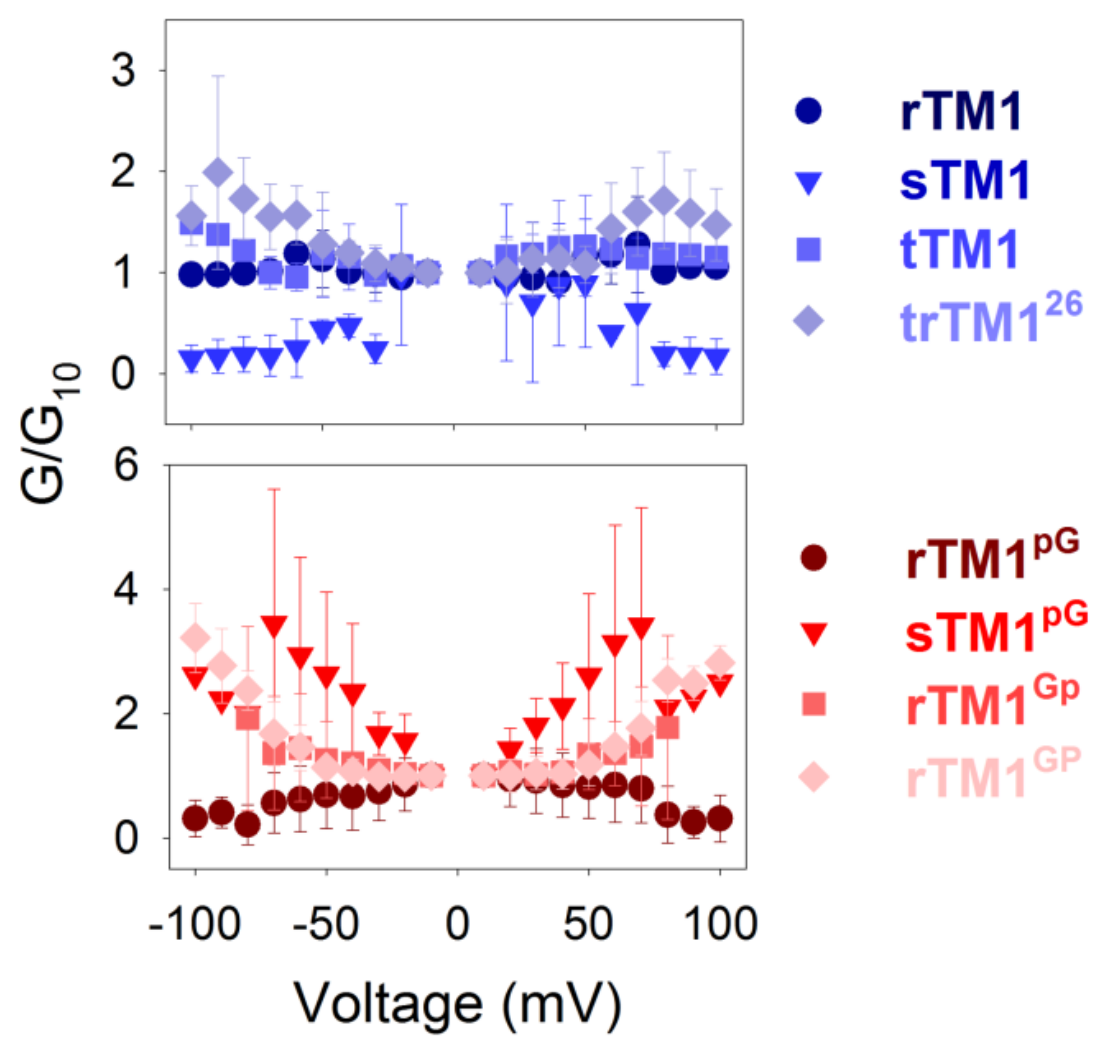

Figure S8b. $G / \mathrm{G}_{10}$ plots were derived from channel conductance $(\mathrm{G}$, in units of $\mathrm{nS})$ obtained at every voltage from $-100 \mathrm{mV}$ to $+100 \mathrm{mV}$, in steps of $10 \mathrm{mV}$. In several experiments with many of the chimeric peptides, we observe an increased frequency of peptide insertion at higher voltages (see Figure S8a). This causes an increase in the measured current at higher voltages, concomitantly increasing the calculated $\mathrm{G} / \mathrm{G}_{10}$ value. Evidence for change in the number of peptides was obtained by comparing the conductance at $+10 \mathrm{mV}$ at the start and end of each electrophysiology (PLB) experiment (see Holding Voltage Experiments in the methods section). The frequency of peptide insertion and assembly in the membrane at voltages $> \pm 40-60 \mathrm{mV}$ is highest for sTM1 ${ }^{\mathrm{pG}}, \mathrm{rTM} 1^{\mathrm{Gp}}$ and $\mathrm{rTM}^{\mathrm{GP}}$. At present, we do not have a convincing explanation for the unusual behavior of these peptides. 

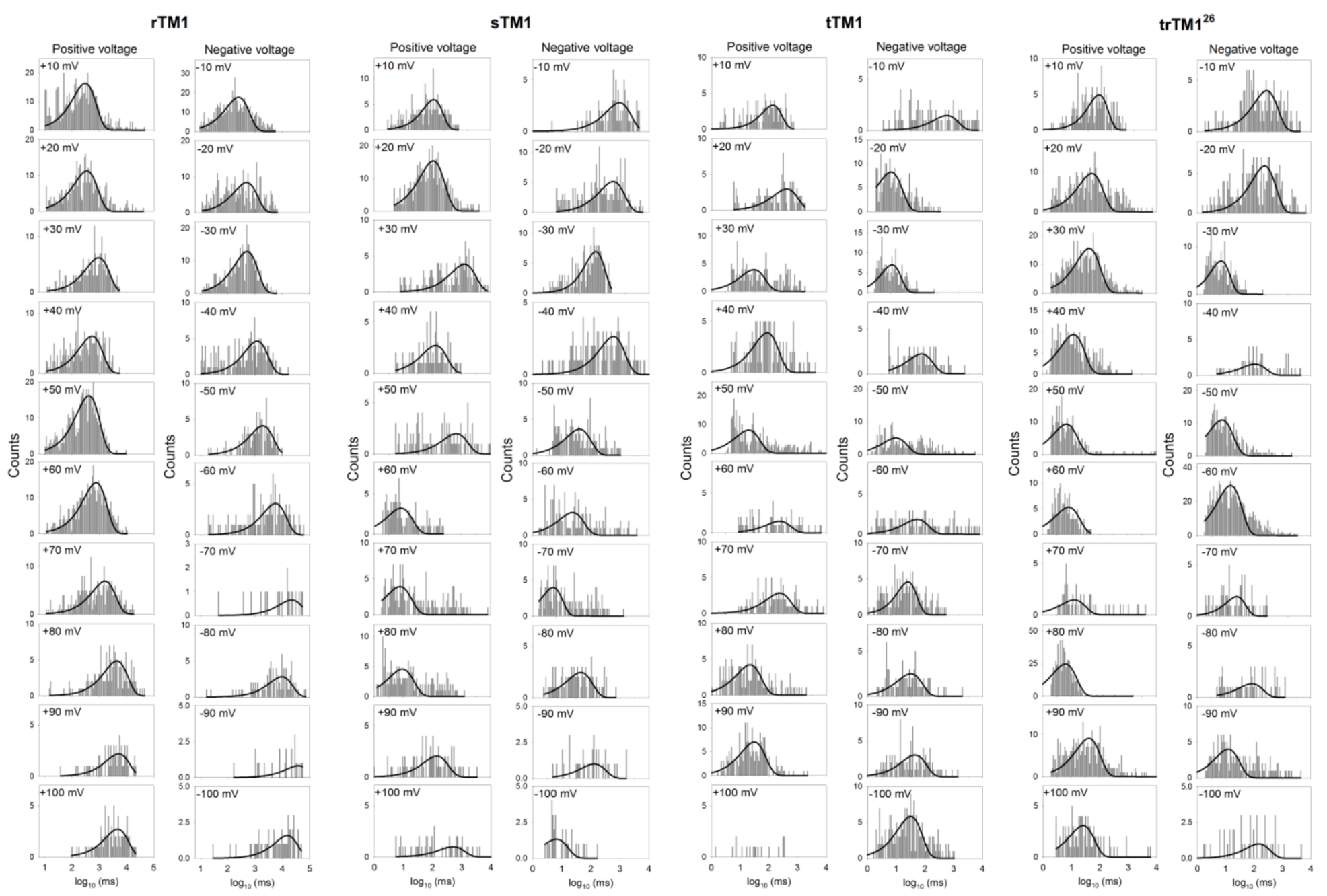

Figure S9. Representative graphs of dwell time calculation for rTM1, sTM1, tTM1 and trTM1 ${ }^{26}$. Event amplitude histograms for various dwell times in ms (grey bars, plotted as $\log _{10}$ scale) at each voltage from $-100 \mathrm{mV}$ to $+100 \mathrm{mV}$, in steps of $10 \mathrm{mV}$ are shown for all four peptides. Data were fitted to a variable metric method in exponential log probability function with the sum of squared errors as a minimization method (shown in black line). All analyses were done on Clampfit v10.3 (Molecular Devices). A minimum of three such recordings were used to derive dwell time values, which is summarized in Figure 3, Figure S10 and Table S2. 
Table S2. Dwell time ${ }^{\S}$ values of channel open state for all chimeric peptides.

\begin{tabular}{|c|c|c|c|c|c|c|c|c|}
\hline Voltage (mV) & rTM1 & rTM1 $^{\mathrm{pG}}$ & rTM1 $^{\mathrm{GP}}$ & rTM1 $^{\mathrm{Gp}}$ & sTM1 & sTM1 $^{\mathrm{pG}}$ & tTM1 & $\operatorname{trTM}^{26}$ \\
\hline-100 & $15184.78^{\#}$ & $28.52 \pm 23.4$ & \# & $\#$ & $29.63 \pm 10.4$ & & $31.79^{@}$ & $145.47^{@}$ \\
\hline-90 & $38373.80^{\#}$ & $19.15 \pm 9.3$ & \# & \# & $68.45 \pm 86.9$ & $\#$ & $44.43^{@}$ & $56.02 \pm 43.4$ \\
\hline-80 & $5035.86 \pm 6400$ & $18.56 \pm 9.8$ & $\#$ & $\#$ & $13.93 \pm 22.1$ & $\#$ & $32.05^{@}$ & $171.32^{@}$ \\
\hline-70 & $11424.25 \pm 14882$ & $12.25 \pm 1$ & $\#$ & $\#$ & $14.88 \pm 10.3$ & $\#$ & $57.00^{@}$ & $55.45^{@}$ \\
\hline-60 & $2421.06 \pm 2669$ & $30.97 \pm 30.2$ & $\#$ & $6.23^{\#}$ & $105.27 \pm 115.7$ & $\#$ & $53.63^{\circledR}$ & $15.20^{@}$ \\
\hline-50 & $1169.74 \pm 1065$ & $17.18 \pm 12.6$ & \# & $5.84 \pm 3.2$ & $100.99 \pm 85.3$ & \# & $7.47 \pm 3.1$ & $63.48 \pm 55.8$ \\
\hline-40 & $772.73 \pm 413$ & $38.58 \pm 37.5$ & \# & $6.95^{\#}$ & $391.36 \pm 290.6$ & $\#$ & $30.02 \pm 39.6$ & $198.07 \pm 88.7$ \\
\hline$-\mathbf{3 0}$ & $1099.56 \pm 1674$ & $19.88 \pm 19.7$ & \# & & $184.48 \pm 283$ & \# & $65.74 \pm 91.5$ & $2539.75 \pm 2528$ \\
\hline-20 & $283.75 \pm 289$ & $16.69 \pm 21$ & $\#$ & $16.72 \pm 7.1$ & $199.98 \pm 256.2$ & \# & $418.90 \pm 698$ & $311.46 \pm 368$ \\
\hline-10 & $1251.44 \pm 1670$ & $10.46 \pm 6$ & $18.11 \pm 18.5$ & $9.88^{\#}$ & $317.29 \pm 402.5$ & \# & $287.29 \pm 398.3$ & $619.85 \pm 163.7$ \\
\hline+10 & $235.60 \pm 218$ & $24.87 \pm 36.6$ & $24.21 \pm 21.6$ & $15.03 \pm 14.2$ & $128.08 \pm 135$ & $14.76 \pm 6.8$ & $572.45 \pm 146.2$ & $69.52 \pm 126.8$ \\
\hline+20 & $475.93 \pm 499$ & $13.63 \pm 8.7$ & $34.82 \pm 35.1$ & $126.71 \pm 201.5$ & $95.24 \pm 107.3$ & $8.25^{\#}$ & $160.21 \pm 221.7$ & $58.72 \pm 78.3$ \\
\hline+30 & $431.55 \pm 445$ & $15.23 \pm 7.5$ & $9.24 \pm 5.24$ & $24.27^{\#}$ & $537.51 \pm 571.4$ & $17.40^{\#}$ & $23.39 \pm 7.30$ & $237.17 \pm 486.5$ \\
\hline+40 & $707.08 \pm 475$ & $38.37 \pm 40.3$ & $\#$ & $6.98^{\#}$ & $89.62 \pm 94.4$ & \# & $35.75 \pm 45.19$ & $229.27 \pm 329.2$ \\
\hline$+\mathbf{5 0}$ & $674.58 \pm 843$ & $87.16 \pm 103.4$ & $\#$ & $32.19 \pm 36.6$ & $381.79 \pm 399$ & $\#$ & $13.85 \pm 8.15$ & $12.81 \pm 8.5$ \\
\hline+60 & $933.26 \pm 861$ & $24.44 \pm 13$ & $\#$ & $7.02^{\#}$ & $116.89 \pm 174.37$ & $\#$ & $234.68^{@}$ & $67.00 \pm 83.1$ \\
\hline+70 & $1154.51 \pm 705$ & $81.79 \pm 59.6$ & \# & $7.49^{\#}$ & $11.00 \pm 4.04$ & \# & $236.96^{@}$ & $9.01 \pm 3.47$ \\
\hline+80 & $2910.75 \pm 1683$ & $43.55 \pm 31.9$ & $\#$ & $\#$ & $20.59 \pm 21.79$ & \# & $22.05^{@}$ & $33.59 \pm 45.25$ \\
\hline+90 & $5140.76^{\#}$ & $32.06 \pm 27.4$ & $\#$ & $\#$ & $66.69 \pm 69.31$ & $\#$ & $30.88^{@}$ & $24.55 \pm 16.1$ \\
\hline+100 & $4738.55^{\#}$ & $32.68 \pm 41.5$ & \# & \# & $214.40 \pm 253.1$ & \# & $572.45^{@}$ & $791.97 \pm 802.7$ \\
\hline
\end{tabular}



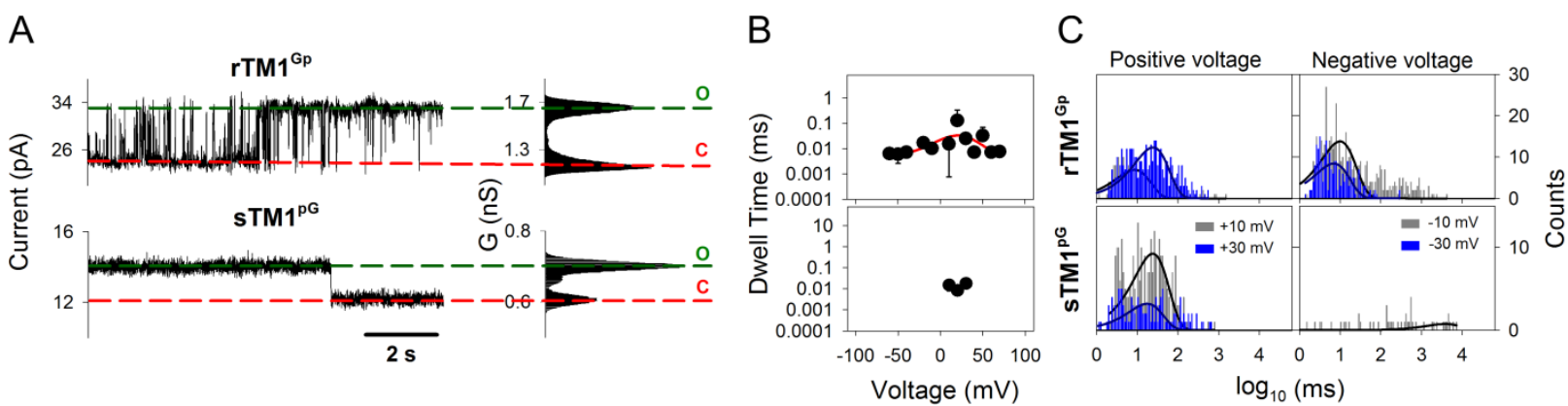

Figure S10 (continued from Figure 3). Representative graphs for holding voltage measurements and dwell time distribution. (A) Representative data for $\mathrm{rTM}^{\mathrm{Gp}}$ and $\mathrm{sTM} 1^{\mathrm{pG}}$ at $+20 \mathrm{mV}$. The channel stays in either the open (green dashed line, O) or low conductance states (red dashed line, C), with defined conductance values. Event amplitude histograms, which represent the probability of channel occurrence in open or low conductance states, are shown on the right for each peptide, and they clearly demarcate the difference in conductance for the low conductance and open channel states. (B) The dwell times at various voltages, derived from fitting the histograms shown in (C). Note that dwell time could not be derived for holding voltages beyond $\pm 70-80 \mathrm{mV}$ for $\mathrm{rTM}^{\mathrm{Gp}}$ and for all voltages except $+10-30 \mathrm{mV}$ for sTM1 ${ }^{\mathrm{pG}}$. This was due to poor channel activity and prolonged residence time of the peptides in either the open or low conductance states. In both peptides, we conclude from the data summarized in (B) that the dwell time values do not change considerably with voltage. (C) Representative event amplitude histograms at $\pm 10 \mathrm{mV}$ (grey bars) and $\pm 30 \mathrm{mV}$ (blue bars), fitted to a variable metric method (solid black line). The dwell times thus derived are plotted in (B). 


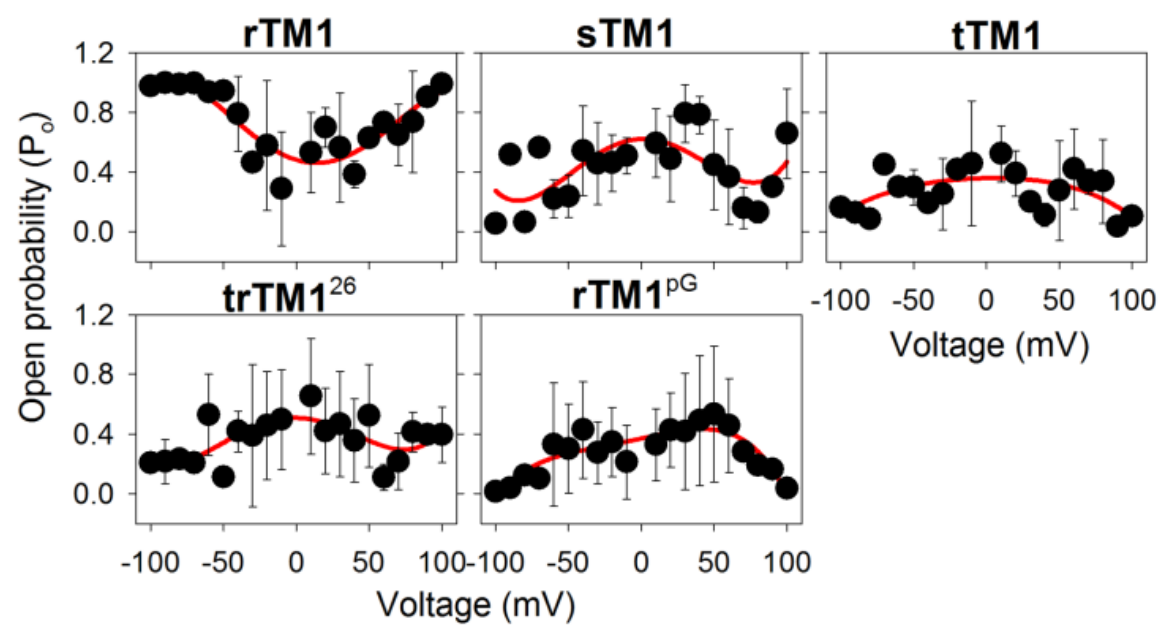

Figure S11. Open probability calculation of single channel recordings. The probability of the channel being in an open state $\left(\mathrm{P}_{\mathrm{o}}\right)$ was calculated by using Clampfit v10.3 analysis software (see methods section). Dwell time and open probability are directly correlated, and rTM1 $\mathrm{P}_{\mathrm{o}}$ values are clearly demarcated from the other peptides of this study. The observed $\mathrm{P}_{\mathrm{o}}$ at $+10 \mathrm{mV}$ is $\sim 0.4-0.5$, and it is similar for all the chimeric peptides. On the other hand, at higher voltages, $\mathrm{P}_{\mathrm{o}}$ values are distinct for $\mathrm{rTM} 1$, and reveal that $\mathrm{rTM} 1$ possesses the highest $\mathrm{P}_{\mathrm{o}}$ of $\sim 1.00$. $\mathrm{P}_{\mathrm{o}}$, along with higher dwell time values (see Figure 3B, Table S2) support our conclusions that rTM1 forms stable ion channels when compared with sTM1, tTM1 trTM1 ${ }^{26}$ and rTM1 ${ }^{\mathrm{pG}}$. 
A

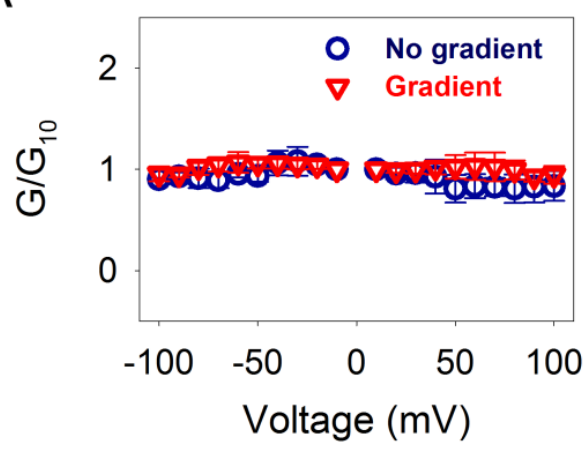

B

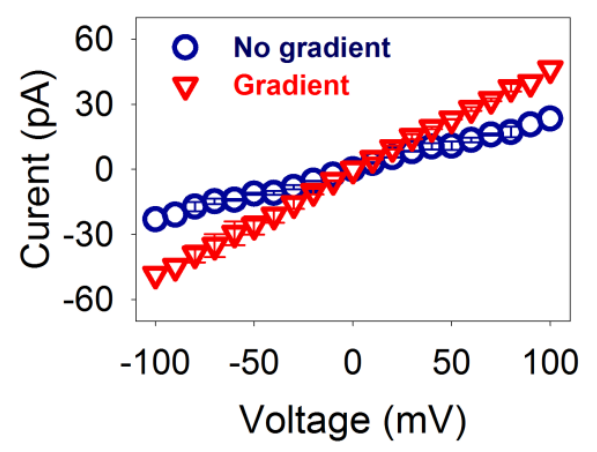

Figure S12a. Ion channel activity measured in the presence of a $\mathrm{KCl}$ gradient shows that rTM1 peptide forms a non-specific ion channel. (A) G/G $\mathrm{G}_{10}$ plot and (B) I-V plot for rTM1 peptide. Data obtained in the absence of a $\mathrm{KCl}$ gradient $(0.5 \mathrm{M} \mathrm{KCl}$ in both the cis and trans chambers; blue circle) or presence of a $\mathrm{KCl}$ gradient $(0.5 \mathrm{M} \mathrm{KCl}$ in the cis chamber and $0.2 \mathrm{M}$ in the trans chamber; inverted red triangle) are shown. All $\mathrm{KCl}$ solutions were prepared in $50 \mathrm{mM}$ phosphate buffer $\mathrm{pH}$ 7.2. We observed a similar conductance for both the conditions, as seen from the $\mathrm{G} / \mathrm{G}_{10}$ plot (A). The I-V plot (B) suggests that the rTM1 peptide channel behaves in a voltageindependent manner. The overall data indicates the rTM1 forms non-selective ion channels. 
A

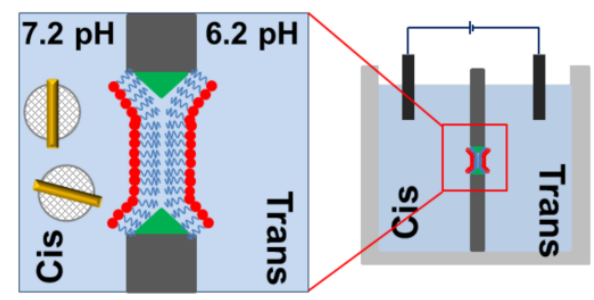

B

C
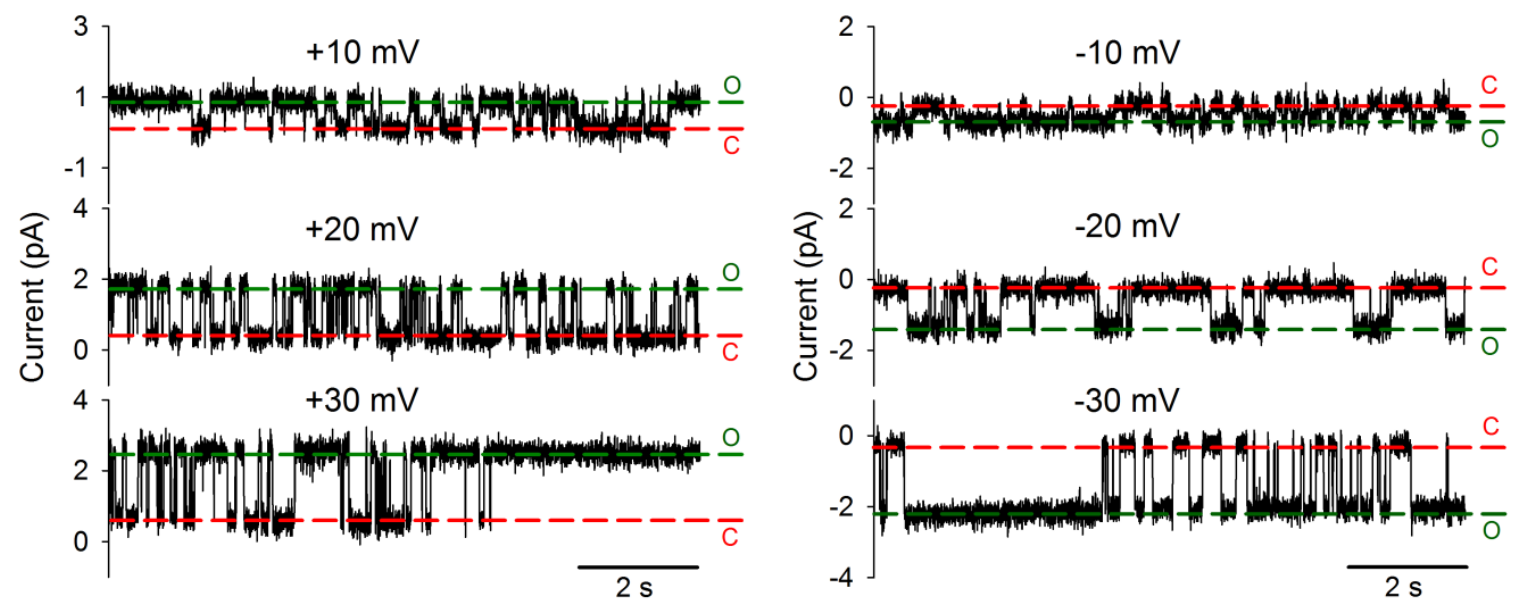

Figure S12b. Ion channel measurements for the rTM1 peptide in the presence of a $\mathrm{pH}$ gradient. (A) Schematic representation of how a $\mathrm{pH}$ gradient is maintained in the PLB experimental setup. The DiPhPC membrane is separated by a symmetric $0.5 \mathrm{M} \mathrm{KCl}$ solution in $50 \mathrm{mM}$ phosphate buffer $\mathrm{pH} 7.2$ and $\mathrm{pH} 6.2$ between the cis and trans chambers, respectively. The peptide is added to the cis chamber and examined for its membrane association behavior. (B and C) Representative holding voltage measurements at each voltage from $+10 \mathrm{mV}$ to $+30 \mathrm{mV}$ (B) and $10 \mathrm{mV}$ to $-30 \mathrm{mV}$ (C) in steps of $10 \mathrm{mV}$. Open (O) and low conductance (C) states of the channel are indicated using dashed lines. The data shows that ion channel activity of rTM1 is retained despite a $\mathrm{pH}$ gradient between the cis and trans chambers. This data implies that a $\mathrm{pH}$ gradient does not influence the ion channel activity of rTM1. 
rTM1

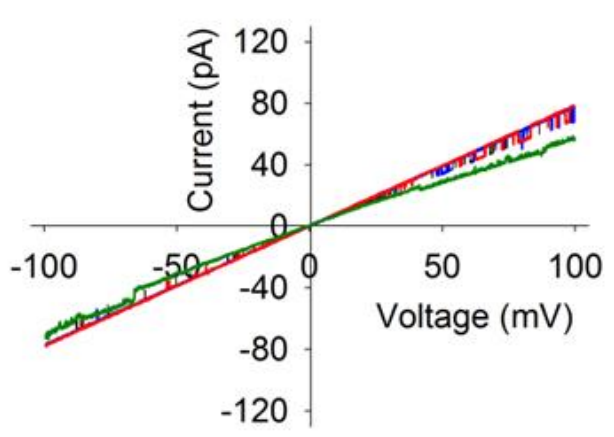

$\mathrm{rTM1}^{\mathrm{GP}}$

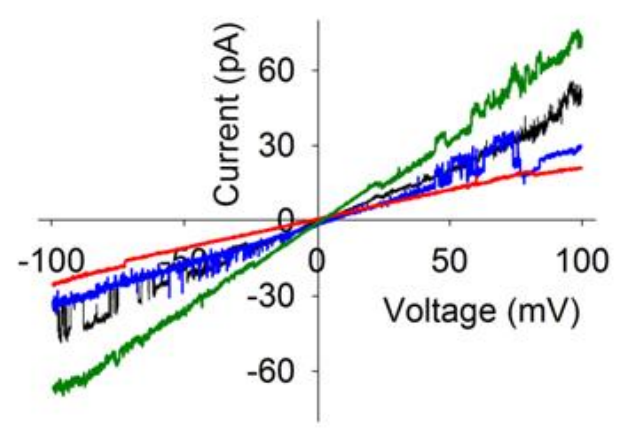

sTM1

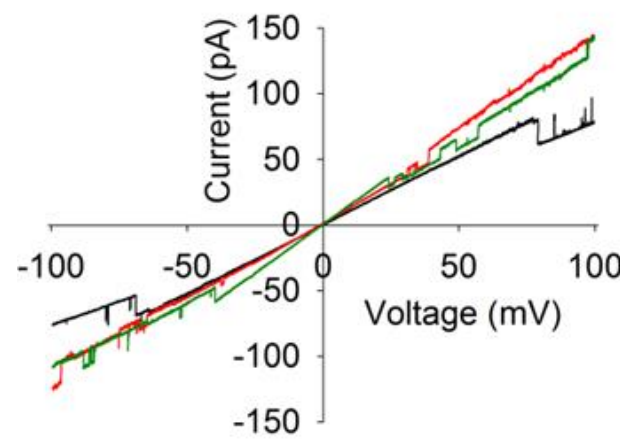

tTM1

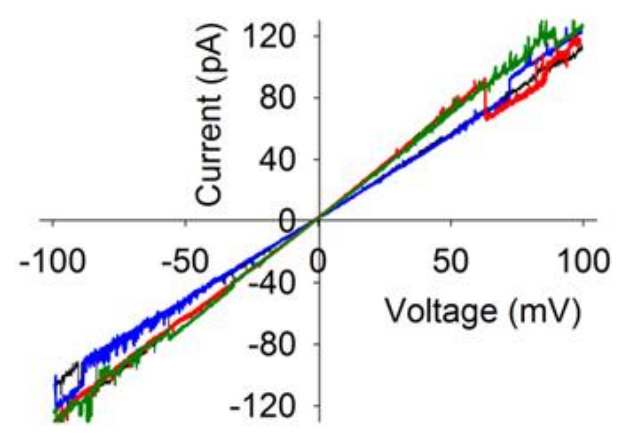

$r T M 1^{p G}$

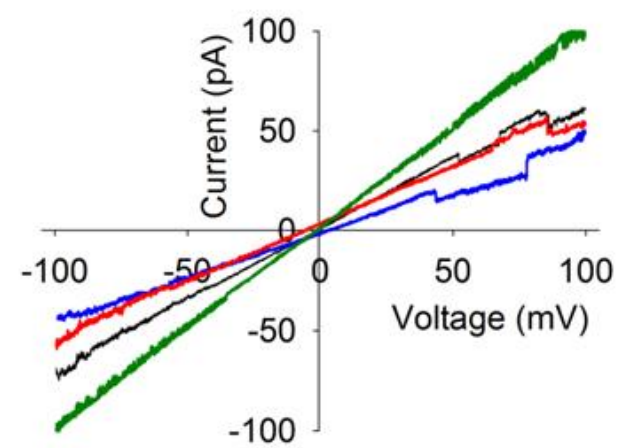

$\mathrm{rTM}^{\mathrm{Gp}}$

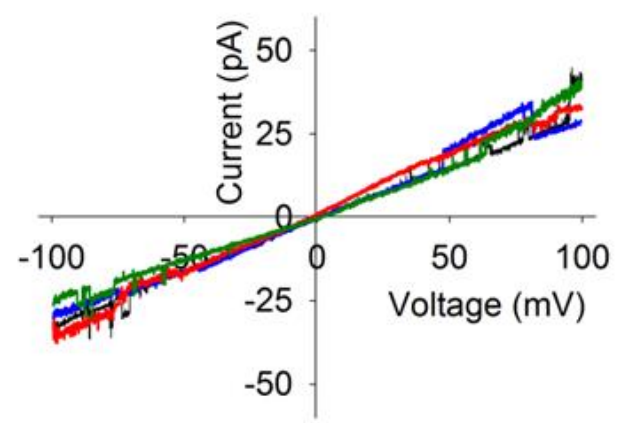

sTM1 $1^{\text {pG }}$

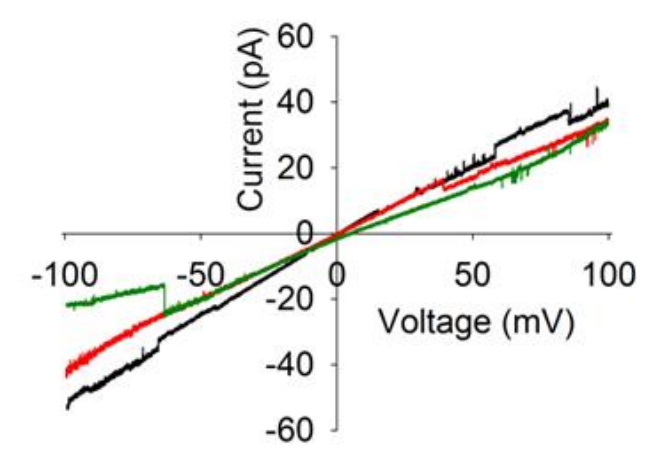

$\operatorname{trTM} 1^{26}$

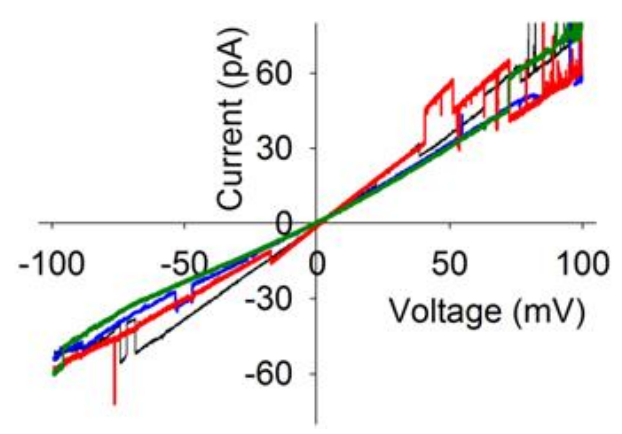

Figure S12c. Representative graphs of voltage ramp measurements for all chimeric peptides show that the channel behavior is voltage-independent. The voltage ramp experiments were carried out from $-100 \mathrm{mV}$ to $+100 \mathrm{mV}$ at the rate of $5 \mathrm{mV} / \mathrm{s}$. All peptides display similar behavior at both positive and negative voltages. The observed current is modulated only by the number of peptides in the membrane. Independent experiments are represented using different colors in each graph. 


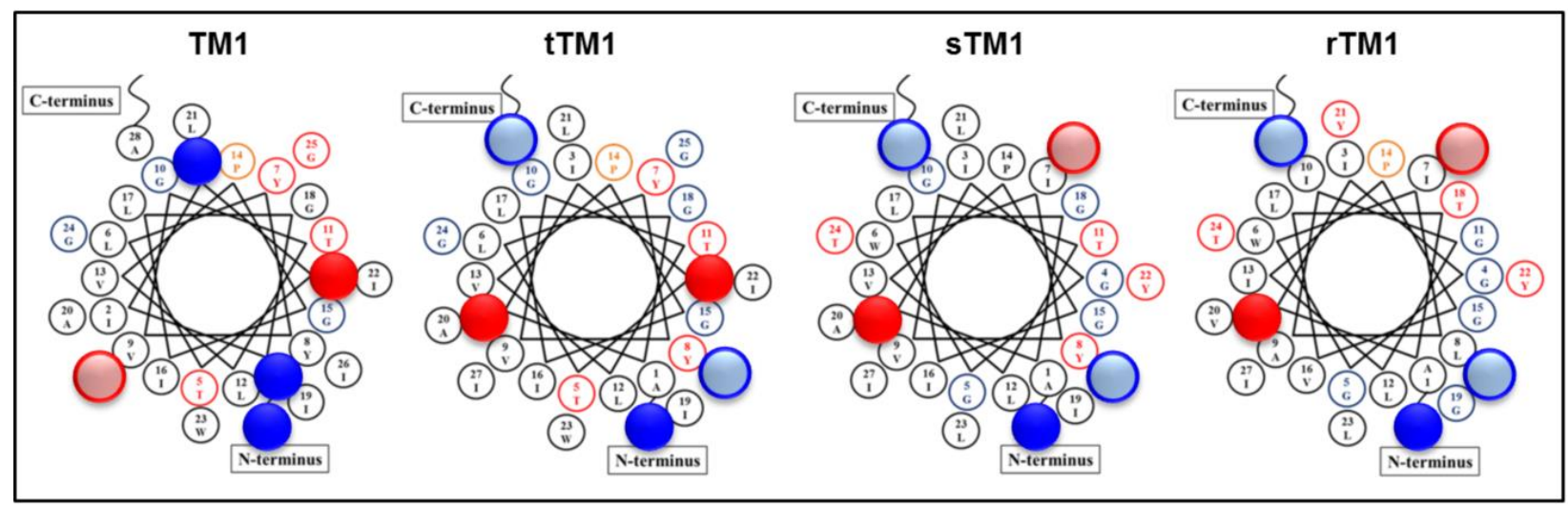

Figure S13 (Continued from Figure 4A). Schematic representation of charge distribution across the chimeric peptides for an ideal helical structure. Four peptides are chosen here to represent increasing extent of strand swapping from the parent peptide (TM1; extreme left) to the completely reversed chimeric peptide (rTM1; extreme right). Shown here is the helical wheel representation of the four peptides, highlighting the amino acid distribution along the helix axis for the four peptides. Blue filled circles denote positively charged sites (N-terminus, lysine and arginine), while red filled circles represent negatively charged centers (aspartate, glutamate). The C-terminus is amidated, and is considered as polar, but uncharged. Solid (bold) fills are used to indicate that the residues are towards the N-terminus, while lighter fills (with bold edges) indicate that the residues are towards the C-terminus. All peptides have three positive and two negative charges, that are asymmetrically distributed, based on the extent of strand swapping. The membrane breaker peptide TM1 and to some extent tTM1 (which shows significant instances of membrane disruption in PLB measurements), show an asymmetric enrichment of charges (+2 and -1) towards the termini. sTM1 and rTM1, which form ion channels in the membrane, have an overall similar charge distribution with a net positive charge only at the Cterminal end. 


\section{REFERENCES:}

1. Lella, M.; Mahalakshmi, R. Pro-Gly Mediated Conformational Switch of Mycobacteriophage D29 Holin Transmembrane Domain I Is Lipid Concentration Driven. Chem. Commun. 2013, 49, 9594-9596.

2. Lella, M.; Kamilla, S.; Jain, V.; Mahalakshmi, R. Molecular Mechanism of Holin Transmembrane Domain I in Pore Formation and Bacterial Cell Death. ACS Chem. Biol. 2016, $11,910-920$.

3. Horn, R. Statistical Methods for Model Discrimination. Applications to Gating Kinetics and Permeation of the Acetylcholine Receptor Channel. Biophys. J. 1987, 51, 255-263.

4. Sigworth, F. J.; Sine, S. M. Data Transformations for Improved Display and Fitting of Single-Channel Dwell Time Histograms. Biophys. J. 1987, 52, 1047-1054. 